ARTICLE

DOI: $10.1038 / s 41467-018-05798-x$

\title{
Biomimetic nanoflowers by self-assembly of nanozymes to induce intracellular oxidative damage against hypoxic tumors
}

\author{
Zhenzhen Wang ${ }^{1,2}$, Yan Zhang ${ }^{1,2}$, Enguo Ju1,2, Zhen Liu¹, Fangfang Cao ${ }^{1,2}$, Zhaowei Chen', \\ Jinsong $\operatorname{Ren}^{1} \&$ Xiaogang Qu (D) ${ }^{1}$
}

Reactive oxygen species (ROS)-induced apoptosis is a promising treatment strategy for malignant neoplasms. However, current systems are highly dependent on oxygen status and/ or external stimuli to generate ROS, which greatly limit their therapeutic efficacy particularly in hypoxic tumors. Herein, we develop a biomimetic nanoflower based on self-assembly of nanozymes that can catalyze a cascade of intracellular biochemical reactions to produce ROS in both normoxic and hypoxic conditions without any external stimuli. In our formulation, PtCo nanoparticles are firstly synthesized and used to direct the growth of $\mathrm{MnO}_{2}$. By adjusting the ratio of reactants, highly-ordered $\mathrm{MnO}_{2} @ P t C o$ nanoflowers with excellent catalytic efficiency are obtained, where PtCo behaves as oxidase mimic and $\mathrm{MnO}_{2}$ functions as catalase mimic. In this way, the well-defined $\mathrm{MnO}_{2} @$ PtCo nanoflowers not only can relieve hypoxic condition but also induce cell apoptosis significantly through ROS-mediated mechanism, thereby resulting in remarkable and specific inhibition of tumor growth.

\footnotetext{
${ }^{1}$ Laboratory of Chemical Biology and State Key Laboratory of Rare Earth Resources Utilization, Changchun Institute of Applied Chemistry, Chinese Academy of Sciences, Changchun, Jilin 130022, China. ${ }^{2}$ University of Chinese Academy of Sciences, Beijing 100039, China. Correspondence and requests for materials should be addressed to J.R. (email: jren@ciac.ac.cn) or to X.Q. (email: xqu@ciac.ac.cn)
} 
eactive oxygen species (ROS) are highly reactive ions and free radicals, including singlet oxygen $\left({ }^{1} \mathrm{O}_{2}\right)$, superoxide radicals $\left(\mathrm{O}_{2}{ }^{-}\right)$, hydroxyl radicals $(\bullet \mathrm{OH})$, and peroxides $\left(\mathrm{O}_{2}{ }^{2-}\right)$, which play imperative roles in numerous physiological processes $^{1,2}$. At lower concentrations, ROS can function as a crucial second messenger to modulate cell signaling, adhesion, migration, and homeostasis ${ }^{3}$. Whereas elevated ROS levels have the capacity to oxidize unsaturated fatty acids in lipids and amino acids of proteins, inducing irreversible damage to vital organelles and DNA, ultimately leading to cell apoptosis and necrosis 4 . Of particular note, owning to different redox states between cancer and normal cells, malignant cells work with a heighted basal level of ROS-mediated signaling, making them more susceptible to the detrimental effects of exogenous ROS than normal cells ${ }^{5,6}$. Therefore, extensive research efforts have been directed towards the design of ROS-generating systems to induce intracellular oxidative stress for cancer therapy.

Particularly, photodynamic therapy (PDT), which employs light to activate photosensitizers to generate ROS, has been considered as the most promising treatment option because of its minimal invasiveness, site-specific activation, and negligible drug resistance ${ }^{7-9}$. However, the relatively low tissue-penetrating depth of light in biological tissue still remains as an intrinsic shortcoming ${ }^{10-12}$. More troublesome, the reliance of PDT on molecular oxygen limits its effectiveness in hypoxic environments, including many solid tumors ${ }^{13-15}$. Alternatively,
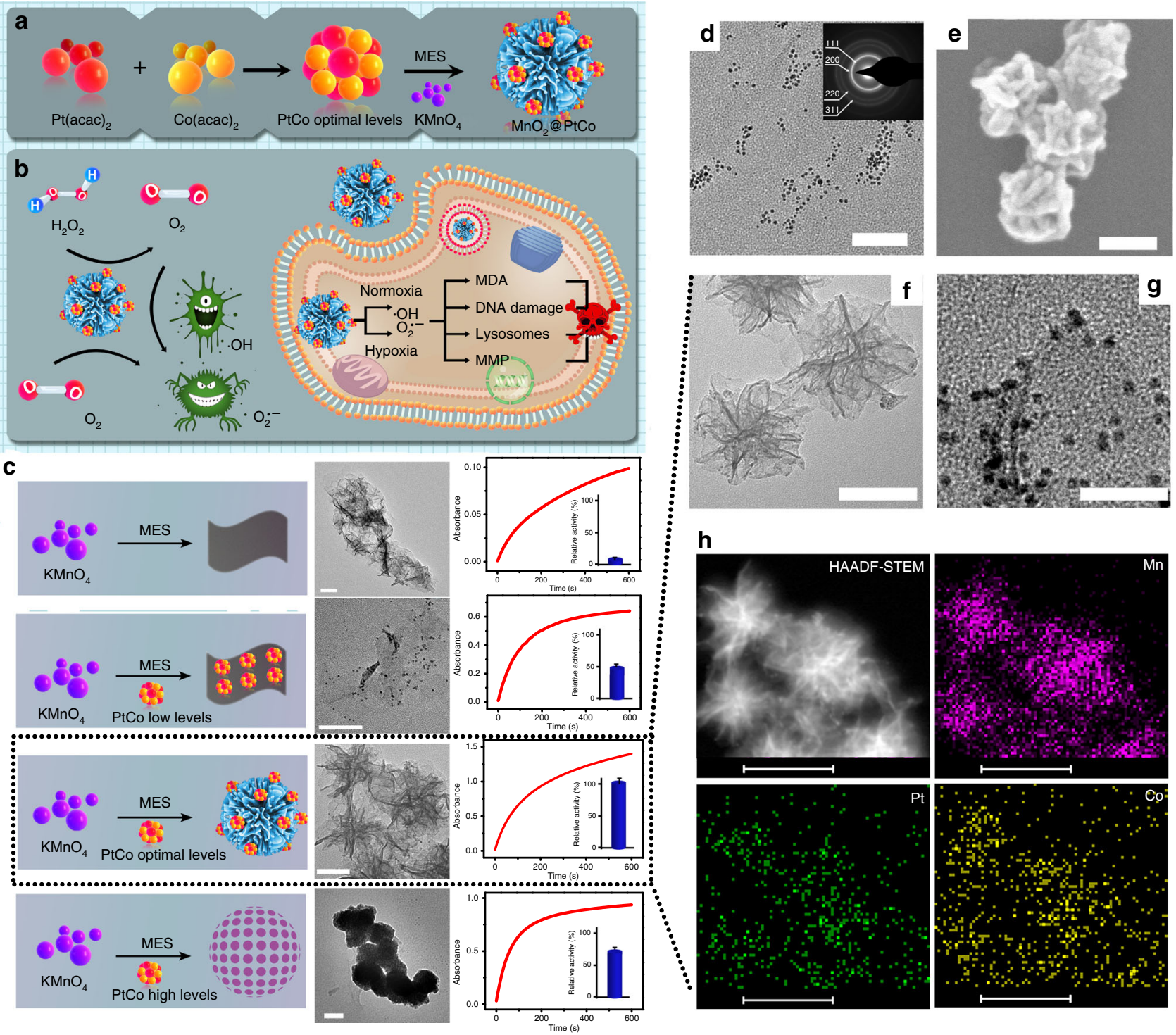

Fig. 1 Synthesis of $\mathrm{MnO}_{2} @$ PtCo nanoflowers. a Schematic illustration showing the self-assembly of nanozymes into well-defined nanoflowers. b Schematic representation of the generation mechanism of ROS and cytotoxicity by $\mathrm{MnO}_{2} @ \mathrm{PtC}$ nanoflowers under different oxygen tensions. c The influence of PtCo concentration on the morphology and catalytic performance of $\mathrm{MnO}_{2} @ \mathrm{PtCo}$ assemblies is directly suggested by TEM images and UV-vis analysis. In the lower concentration, $\mathrm{PtCo}$ nanoparticles could promote and stabilize $\mathrm{MnO}_{2}$ crystal to form two-dimensional nanosheets. With increasing PtCo concentration, it could induce the self-assembly of $\mathrm{MnO}_{2} @ \mathrm{PtC}$ nanosheets to form nanoflower. Nevertheless, further increasing the concentration of PtCo would lead to an increase in the level of self-assembly and therefore cause the formation of aggregated $\mathrm{MnO}_{2} @ \mathrm{PtCo}$ nanospheres. Scale bars are 50 nm. Data were presented as mean \pm s.d. $(n=5)$. d TEM image of PtCo nanozymes (inset: SAED pattern). Scale bar is $50 \mathrm{~nm}$. SEM (e) and TEM (f) image of $\mathrm{MnO}_{2} @$ PtCo nanoflowers. Scale bars are 100 nm. g HRTEM image of $\mathrm{MnO}_{2} @$ PtCo nanoflowers. Scale bar is 20 nm. $\mathbf{h}$ The high-angle annular dark-field (HAADF)-STEM image of $\mathrm{MnO}_{2} @ P t C o$ nanoflowers, and corresponding TEM element mappings of the Mn K-edge, K-edge Pt, and Co K-edge signals. Scale bars are $100 \mathrm{~nm}$ 

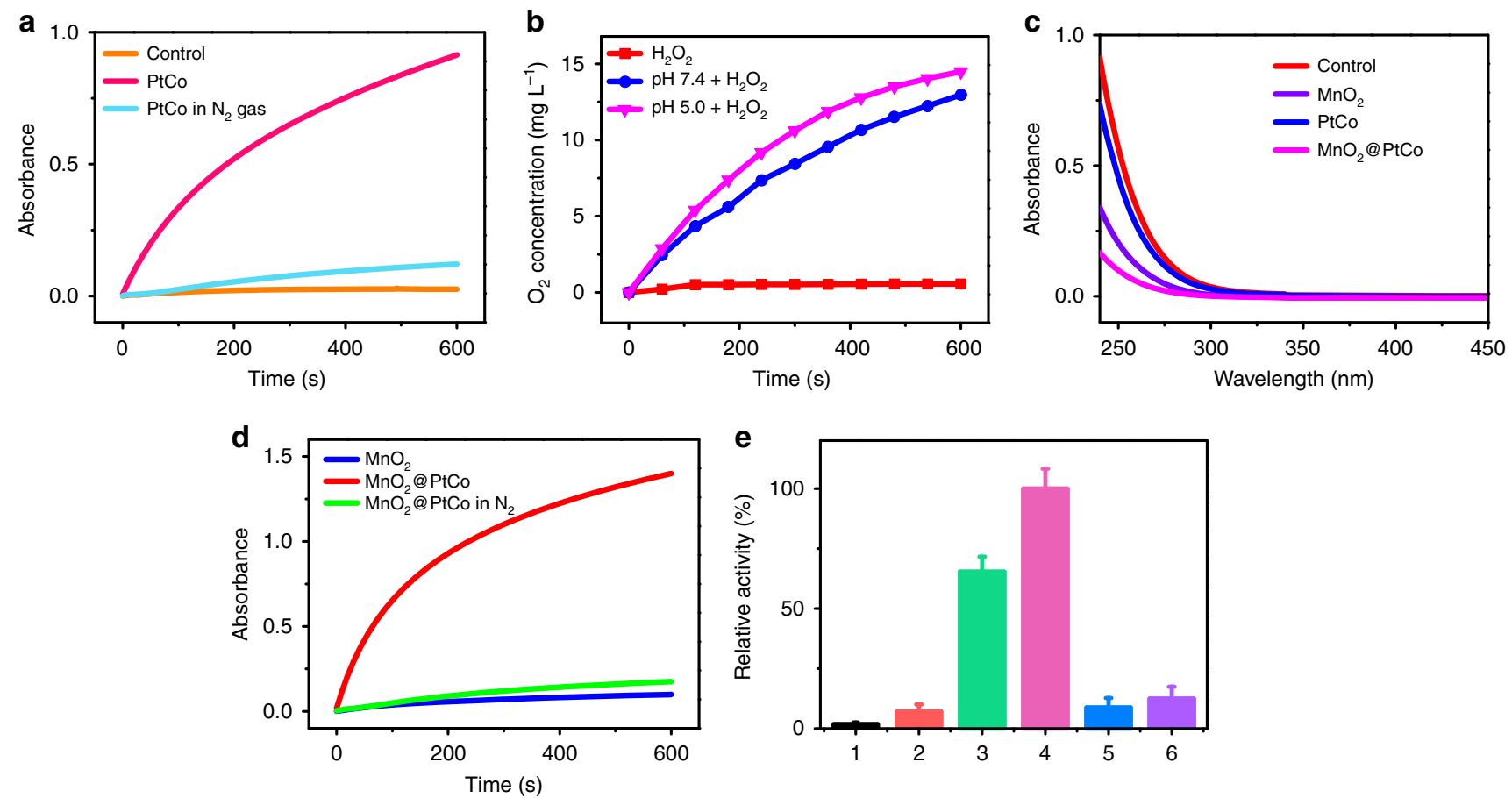

Fig. 2 Multi-enzyme activity of $\mathrm{MnO}_{2} @ P t C o$ nanoflowers in normoxia. a The study of PtCo nanozymes' oxidase-like activity. Time-dependent absorbance changes at $652 \mathrm{~nm}$ of TMB in the presence of PtCo at $\mathrm{N}_{2}$ gas (mimicking hypoxic condition) or not. $\mathbf{b}$ Oxygen generation in $\mathrm{H}_{2} \mathrm{O}_{2}$ solution with $\mathrm{MnO}_{2}$ added under different pH values (7.4 and 5.0). c The study of $\mathrm{MnO}_{2}$ component's CAT-like activity. UV-vis spectra of remain $\mathrm{H}_{2} \mathrm{O}_{2}$ were recorded after reacting with different nanomaterials. d The study of $\mathrm{MnO}_{2} @ \mathrm{PtC}$ nanoflowers' oxidase-like activity. Time-dependent absorbance changes at $652 \mathrm{~nm}$ of TMB with different treatments. e The qualitative analysis of different nanomaterials' oxidase activity. 1: control; 2: $\mathrm{MnO}_{2} ; 3: \mathrm{PtCo}$;: $\mathrm{MnO}_{2} @ \mathrm{PtCo} ; 5: \mathrm{PtCo}$ in $\mathrm{N}_{2}$ gas; 6: $\mathrm{MnO}_{2} @ \mathrm{PtCo}$ in $\mathrm{N}_{2}$ gas. Data were presented as mean \pm s.d. $(n=5)$

sonodynamic therapy (SDT) that comprises ultrasound and sonosensitzer as ROS generator has been developed recently and witnessed some exciting results 16,17 . Although promising, such strategy would induce hyperthermia effect to surrounding normal tissues as well as confer the treatment outcomes with respectable complexity and variability. Therefore, it is highly desired to develop a paradigm that not only can directly generate exogenous ROS inside tumors without any external stimulus, but also overcome the hypoxic microenvironment of tumors for magnifying ROS generation.

Nanozymes that integrate the functions of both nature enzymes and nanomaterials have sparked increasing interest due to their higher stability against stringent conditions, controlled synthesis at low cost and tunable catalytic activities ${ }^{18-20}$. Such unique advantages make nanozymes widely exploit in biomedical applications, such as biosensing, disease diagnosis, tissue engineering, etc. ${ }^{21-23}$. Recently, a special focus has been made on probing the ability of nanozymes in controlling intracellular biochemical reactions to treat various diseases including antiaging, stroke, and inflammation ${ }^{24,25}$. For example, $\mathrm{V}_{2} \mathrm{O}_{5}$, Prussian blue and $\mathrm{Fe}_{3} \mathrm{O}_{4}$ nanomaterials with antioxidant enzyme-like activity under neutral $\mathrm{pH}$ condition have been demonstrated to catalyze the reduction of cytotoxic ROS into non-toxic products inside cells and prevent them against oxidative stress ${ }^{26-29}$. However, along this line, the strong oxidizing capacity of nanozymes in acidic conditions has long been ignored, particularly in the field of cancer therapy. Concerning the acidic tumor microenvironment and the nanozyme's ability to modulate intracellular biochemical processes, we envision that the nanozymes-based platform can realize tumor-specific therapy and resolve the lingering problems of current ROS-mediated therapy systems.

Herein, we construct a biomimetic nanoflower based on selfassembly of nanozymes that is capable of generating ROS in both normoxic and hypoxic conditions with a noninvasive and facile manner, where any external stimulus is not needed. In our design, PtCo nanoparticles behave as oxidase mimics whereas $\mathrm{MnO}_{2}$ is used to mimic catalase (CAT), both of which assemble into highordered nanoflowers by simply adjusting the amount of reactants (Fig. 1a). PtCo nanozyme can catalyze the oxidation reaction cascades to induce intracellular oxidative damage, thereby leading to efficient therapeutic outcome. Meanwhile, with the intrinsic CAT-like activity, $\mathrm{MnO}_{2}$ component has the ability to induce the decomposition of $\mathrm{H}_{2} \mathrm{O}_{2}$ into $\mathrm{O}_{2}$ rapidly and efficiently, which not only surmounts the intrinsic hypoxic environment of tumors but, importantly, makes our therapeutic system independent on $\mathrm{O}_{2}$. In this way, chemodynamic therapy is readily realized by utilizing endogenous chemical energy to generate ROS, without the need for external energy input and local oxygen, thus circumventing the limitations posed by the PDT and SDT (Fig. 1b). Both in vitro and in vivo experiments demonstrate that $\mathrm{MnO}_{2} @ \mathrm{PtCo}$ nanoflowers dramatically induce intracellular oxidative damage under different oxygen tensions as well as inhibit tumor growth in xenograft-bearing mice. More importantly, the $\mathrm{pH}$-dependent catalytic functions of nanozymes make the therapeutic outcome specificity for tumors, leaving normal tissues unharmed. Therefore, we believe that the present study may open up a leverage for cancer therapy and ignite the further explorations and applications of nanozymes in various fields, such as bioimaging, detoxification and catalysis.

\section{Results}

Design and construction of $\mathrm{MnO}_{2} @ \mathrm{PtCo}$ nanoflowers. To substantiate our design, PtCo nanozyme was specially chosen as oxidase mimic on account of its advantages of easy preparation, excellent catalytic ability in a broad $\mathrm{pH}$ range, smaller size, good 
a

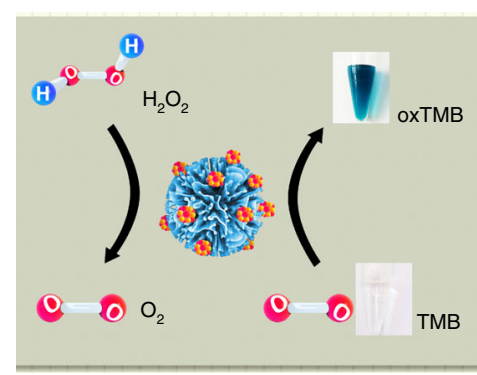

C

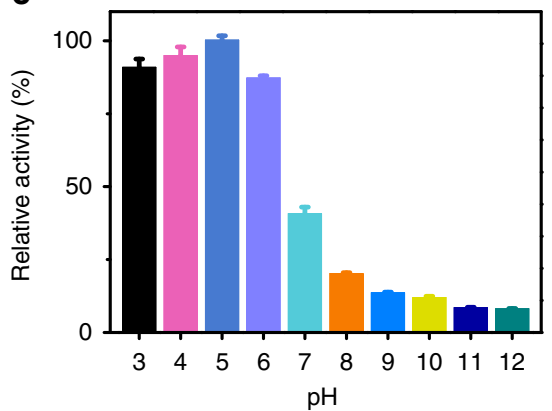

b

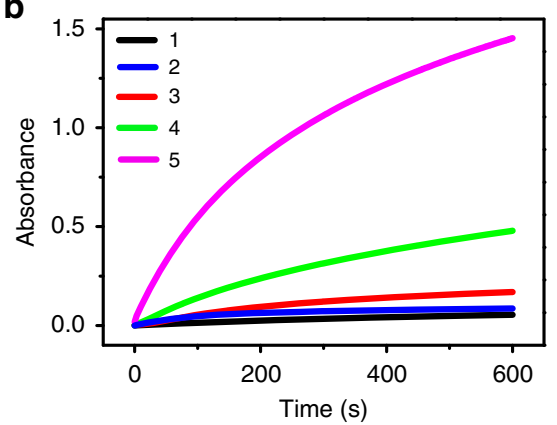

d

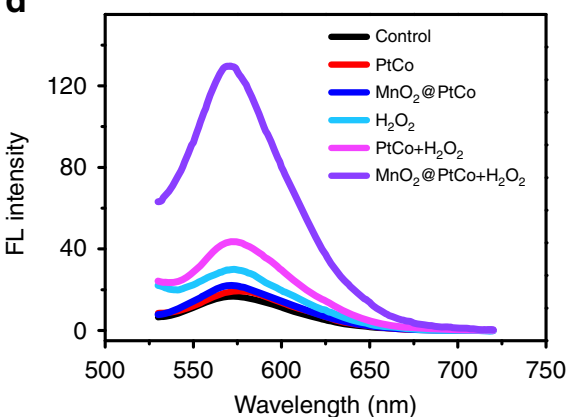

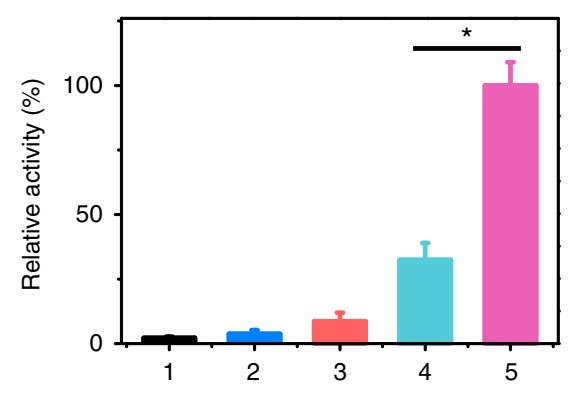

e

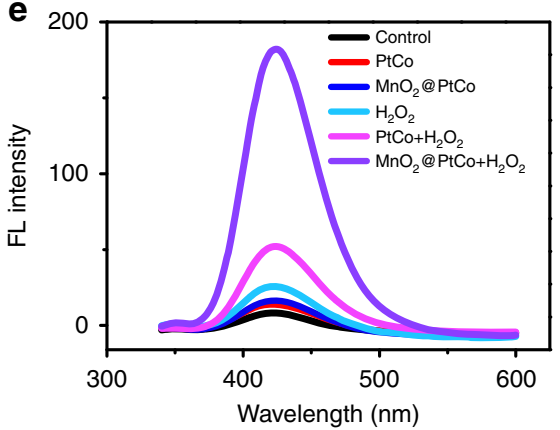

f

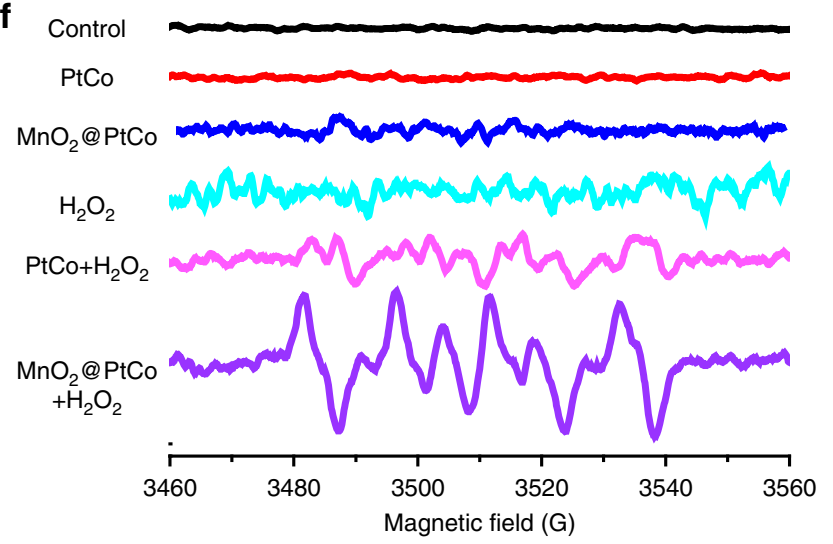

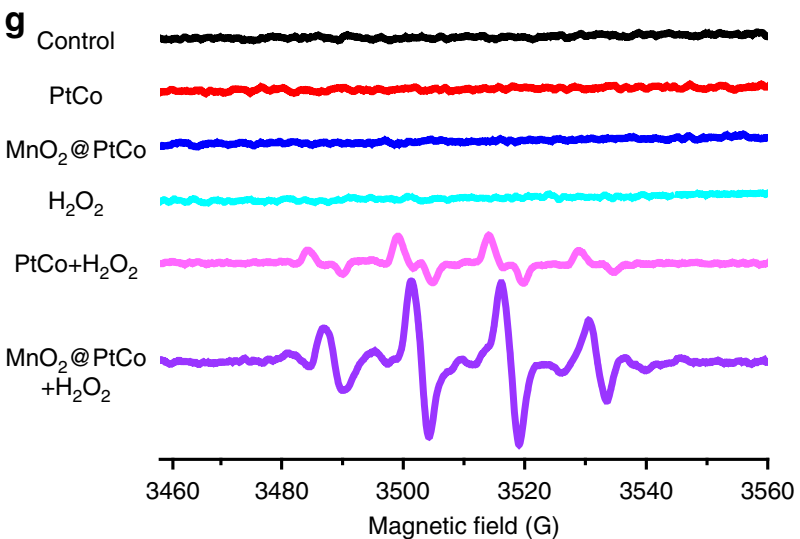

Fig. 3 Multi-enzyme activity and catalytic mechanism of $\mathrm{MnO}_{2} @$ PtCo nanoflowers in hypoxia. a Schematic illustration of catalytic reactions of $\mathrm{MnO}_{2} @$ PtCo nanoflowers in the hypoxic $\mathrm{H}_{2} \mathrm{O}_{2}$ condition. b The oxidase-like activity of various nanomaterials by monitoring the absorption of TMB at 652 $\mathrm{nm}$ and the qualitative analysis of their catalytic activity in the hypoxic $\mathrm{H}_{2} \mathrm{O}_{2}(100 \mu \mathrm{M})$ environment. 1: $\mathrm{H}_{2} \mathrm{O}_{2}$ alone; 2: PtCo; 3: MnO $@$ PtCo; 4: PtCo + $\mathrm{H}_{2} \mathrm{O}_{2} ; 5: \mathrm{MnO}_{2} @ \mathrm{PtCo}+\mathrm{H}_{2} \mathrm{O}_{2}$. Asterisks indicate significantly differences $\left({ }^{\star} P<0.01,{ }^{\star \star} P<0.005,{ }^{\star \star \star} P<0.001\right.$ ), analyzed by unpaired Student's two-sided $t$ test. c The influence of pH on the catalytic ability of $\mathrm{MnO}_{2} @ \mathrm{PtC}$ nanoflowers. d Fluorescence spectra of hydroethidine incubated with $\mathrm{MnO}_{2} @ \mathrm{PtCo}$ nanoflowers in the hypoxic $\mathrm{H}_{2} \mathrm{O}_{2}(100 \mu \mathrm{M})$ condition to demonstrate the presence of $\mathrm{O}_{2}{ }^{\cdot-}$. e Fluorescence spectra of $\mathrm{TA}$ incubated with $\mathrm{MnO}_{2} @ P t C o$ nanoflowers in the hypoxic $\mathrm{H}_{2} \mathrm{O}_{2}(100 \mu \mathrm{M})$ condition to demonstrate the generation of $\cdot \mathrm{OH}$. $\mathbf{f} \mathrm{ESR}$ spectra of $\mathrm{BMPO} / \cdot \mathrm{OOH}$ adducts from different groups in the hypoxic $\mathrm{H}_{2} \mathrm{O}_{2}(100 \mu \mathrm{M})$ condition upon addition of DMSO. $\mathbf{g}$ ESR spectra of BMPO/ $\cdot \mathrm{OH}$ adducts were collected from different samples in the hypoxic $\mathrm{H}_{2} \mathrm{O}_{2}(100 \mu \mathrm{M})$ condition upon addition of SOD. Data were presented as mean \pm s.d. $(n=5)$

dispersity and stability compared with other oxidase mimics ${ }^{19,30-}$ 32. We initially studied the influence of different atomic ratio Pt/ Co on the resultant nanoparticles' enzyme-mimic activity. As illustrated in Supplementary Fig. 1a, b, when the atomic ratio of Pt/Co was 3:1, PtCo nanoparticles exhibited the best catalytic activity, which was consistent with previous report ${ }^{32}$. Moreover, no significant $\mathrm{Co}^{2+}$ ions were released in cell culture medium and blood sample after incubation of 8, 24, and $48 \mathrm{~h}$ (Supplementary Fig. 1c), indicating a good stability. Consequently, PtCo nanoparticles at the molar ratio of 3:1 were used in our work. A typical transmission electron microscopy (TEM) image showed that these well-prepared PtCo nanoparticles were uniform in size with a diameter of around $3 \mathrm{~nm}$ (Fig. 1d). The interfringe distance of lattice fringes in high-resolution TEM (HRTEM) image and the characteristic diffraction spots in selected area electron diffraction (SAED) pattern vividly revealed the formation of the bimetallic phase of Pt and Co, which further confirmed by X-ray diffraction (XRD) peak and X-ray photoelectron spectroscopy (XPS) analysis (Supplementary Fig. 2). To obtain $\mathrm{MnO}_{2} @$ PtCo assemblies, the PtCo nanoparticles were utilized to direct the growth of $\mathrm{MnO}_{2}$. Intriguingly, we found that the amount of PtCo played a crucial role in the formation of $\mathrm{MnO}_{2} @ \mathrm{PtCo}$. As illustrated in Fig. 1c, without PtCo or higher concentrations of PtCo presented, the resulting $\mathrm{MnO}_{2} @ \mathrm{PtCo}$ nanomaterials tended to aggregate and form precipitates, both of which exhibited low catalytic capacity. Despite the well-dispersed $\mathrm{MnO}_{2} @ \mathrm{PtCo}$ nanosheets were obtained in the presence of low dose of PtCo, the lower enzymatic activity was observed. Comparatively, when increasing the dose of 
PtCo to optimal level, the assembly of nanozymes in a hierarchical manner with intricate flower-like nanoarchitecture was realized (Fig. 1c, e, f), which provided a significant impetus in mimicking the structure of nature enzyme ${ }^{33}$, thereby offering the highest catalytic performance. Moreover, the enlarged picture of $\mathrm{MnO}_{2} @$ PtCo nanoflowers in Fig.1g demonstrated that PtCo nanoparticles were uniformly dispersed on the surface of nanoflower. The mechanism of PtCo to drive the self-assembly of $\mathrm{MnO}_{2} @$ PtCo nanomaterials may arise from PtCo nanoparticles' abundant surface functional groups (Supplementary Fig. 3), which endows them with the ability to behave as the heterogeneous nucleation sites for $\mathrm{MnO}_{2}$ growth ${ }^{34}$. To investigate the state of $\mathrm{Mn}$ in the nanoflowers, XPS analysis was performed. Binding-energy peaks were observed for $\mathrm{Mn} 2 p_{1 / 2}$ and $\mathrm{Mn} 2 p_{3 / 2}$ at 641.9 and $653.6 \mathrm{eV}$ respectively (Supplementary Fig. 4), which were typical values for $\mathrm{Mn}^{4+}$, suggesting the formation of $\mathrm{MnO}_{2}{ }^{35}$. Meanwhile, uniform distribution of $\mathrm{Mn}, \mathrm{Pt}$, and $\mathrm{Co}$ in Fig. 1h further illustrated the successful formation of $\mathrm{MnO}_{2} @$ PtCo multi-nanozymes. The content ratio of $\mathrm{MnO}_{2}$ to $\mathrm{PtCo}$ in $\mathrm{MnO}_{2} @ \mathrm{PtCo}$ nanoflowers was determined to be $4: 1$ by energy dispersive X-ray spectroscopy (EDX) analysis (Supplementary Fig. 5). Besides, dynamic light scattering (DLS) data showed that the resultant nanoflowers had a good dispersity with an average diameter of about $200 \mathrm{~nm}$, which did not change during 7 days of incubation in both PBS and DMEM containing $10 \%$ fetal bovine serum (FBS), as illustrated in Supplementary Fig. 6. Moreover, the morphology of $\mathrm{MnO}_{2} @$ PtCo nanoflowers has little change after 7 days' incubation (Supplementary Fig. 7), illustrating their long-term stability in culture media.

Catalytic ability of $\mathrm{MnO}_{2} @ P t C o$ nanoflowers. The oxidase-like activity was firstly investigated by real-time monitoring the change in the substrate 3,3,5,5'-tetramethylbenzidine (TMB) absorption at $652 \mathrm{~nm}$. As illustrated in Fig. 2a, PtCo nanoparticles could effectively catalyze TMB oxidation in normoxia, whereas in hypoxia, their catalytic ability was vanished, revealing PtCo component has oxidase-like activity. Note that most tumors tend to develop a hypoxic region ${ }^{36}$, where catalytic capacity of PtCo nanozyme will be compromised. To surmount this problem, $\mathrm{MnO}_{2}$ nanomaterials with intrinsic CAT-like activity were employed ${ }^{29}$. Moreover, $\mathrm{MnO}_{2}$ could also react with $\mathrm{H}_{2} \mathrm{O}_{2}$ and $\mathrm{H}^{+}$ to produce $\mathrm{O}_{2}{ }^{37}$, thereby holding great attractive to overcome tumor hypoxia. As shown in Fig. 2b and Supplementary Fig. 8, clear gas bubbles and dissolved $\mathrm{O}_{2}$ were observed after $\mathrm{H}_{2} \mathrm{O}_{2}$ $(100 \mu \mathrm{M}$, mimicking tumor microenvironment) was added into tubes containing $\mathrm{MnO}_{2}$ under both $\mathrm{pHs}(7.4,5.0)$. Moreover, the concentration of $\mathrm{H}_{2} \mathrm{O}_{2}$ was decreased in the sample containing $\mathrm{MnO}_{2}$ components significantly (Fig. 2c), indicating $\mathrm{MnO}_{2}$ could function as a good CAT mimic. In parallel to mimicking CAT, $\mathrm{MnO}_{2}$ components also possessed peroxidase-like activity in a pH-dependent manner (Supplementary Fig. 9a, b), in accordance with previous reports ${ }^{38,39}$. Subsequently, we embarked on investigating which kind of enzyme activity $\mathrm{MnO}_{2}$ showed in a tumor-mimicking microenvironment $\left(\mathrm{pH} 6.8, \mathrm{H}_{2} \mathrm{O}_{2} 100 \mu \mathrm{M}\right)$. As presented in Supplementary Fig. 9c, d, the concentration of oxidized TMB was calculated to be $16.7 \mu \mathrm{M}$ by the Beer-Lambert Law, indicating $16.7 \%$ of $\mathrm{H}_{2} \mathrm{O}_{2}$ was involved in the peroxidase reaction of $\mathrm{MnO}_{2}$. Comparatively, $70.6 \%$ of $\mathrm{H}_{2} \mathrm{O}_{2}$ was involved in the CAT reaction of $\mathrm{MnO}_{2}$, suggesting $\mathrm{MnO}_{2}$ mainly exhibited CAT-like activity in tumor microenvironment. Benefiting from CAT-like activity of $\mathrm{MnO}_{2}$ and oxidase-like activity of PtCo, $\mathrm{MnO}_{2} @$ PtCo nanoflowers exerted both significant CAT (Fig. 2c) and oxidase-like activity (Fig. 2d), and higher than their counterparts (Fig. 2e). The corresponding control experiments demonstrated that the higher enzymatic activity of our nanoflowers was not stemmed from simply physical mixing (Supplementary Fig. 10a, b), which may be attributed to the larger surface area and confinement effect of nanoflowers. Importantly, the catalytic capacity of $\mathrm{MnO}_{2} @$ PtCo nanoflowers not only enhanced with the increasing concentration but also possessed broad substrate recognition ability (Supplementary Fig. 10c, d).

Inspired by the CAT-like and oxidase-like activity of $\mathrm{MnO}_{2} @ \mathrm{PtCo}$, we then investigated whether these multinanozyme assemblies could catalyze the cascade oxidation reactions in hypoxia. Since $\mathrm{MnO}_{2} @$ PtCo nanoflowers possessed CAT-like and peroxidase-like activity in an acidic $\mathrm{H}_{2} \mathrm{O}_{2}$ condition, we initially evaluated which kind of enzyme activity $\mathrm{MnO}_{2} @$ PtCo nanoflowers showed. As shown in Supplementary Fig. 11, $\mathrm{MnO}_{2} @$ PtCo nanoflowers primarily exhibited CAT-like activity in tumor microenvironment, which could couple with the oxidative reaction of nanoflowers to generate ROS and then induce cellular oxidative damage. As expected, $\mathrm{MnO}_{2} @ \mathrm{PtCo}$ nanoflowers exhibited excellent oxidative ability in the hypoxic $\mathrm{H}_{2} \mathrm{O}_{2}$ environment (Fig. 3b), which could be attributed to the cooperation of between CAT and oxidase of nanoflowers. Moreover, the quantitative analysis showed that the relatively catalytic activity of $\mathrm{MnO}_{2} @ P t C o$ nanoflowers was three times higher than that of PtCo nanozymes, demonstrating our nanoflowers were $\mathrm{O}_{2}$ self-supplying catalysts by taking tumor microenvironment. Furthermore, the effect of $\mathrm{pH}$ and temperature on the catalyze activity of $\mathrm{MnO}_{2} @ \mathrm{PtCo}$ nanoflowers as well as their catalytic stability under physiological conditions were investigated (Fig. 3c and Supplementary Figs. 12, 13). We found that our nanoflowers not only exhibited high activity over a broad $\mathrm{pH}$ (2.5-6.8) and temperature range but also retained significant enzymatic activity in an intracellular microenvironment, providing an essential prerequisite for subsequent cancer therapy. More importantly, $\mathrm{MnO}_{2} @$ PtCo nanoflowers still possessed outstanding catalytic ability over 7 days of incubation in both PBS buffer $(\sim 92 \%)$ and cell culture medium $(\sim 87 \%)$, as demonstrated in Supplementary Fig. 14.

Catalytic mechanism of $\mathbf{M n O}_{2} @ P t C o$ nanoflowers. To elucidate the catalytic mechanism of $\mathrm{MnO}_{2} @$ PtCo nanoflowers, the possible produced active intermediates during the reaction were determined. A dramatic increase in fluorescence intensity of hydroethidine, one highly selective fluorescence probe for $\mathrm{O}_{2}{ }^{-10}$, was observed for $\mathrm{MnO}_{2} @$ PtCo nanoflowers treatment (Supplementary Fig. 15), demonstrating that their capability to generate $\mathrm{O}_{2}{ }^{\bullet-}$. Besides, significant fluorescence enhancement of 2hydroxyterephtthalic acid (HA) was also seen (Supplementary Fig. 16), suggesting $\bullet \mathrm{OH}$ production. Conversely, a few amount of ${ }^{1} \mathrm{O}_{2}$ was generated when $\mathrm{MnO}_{2} @ P t C o$ nanoflowers incubated with 1,3-diphenylisobenzofuran (DPBF) indicator, even increasing their concentrations to $100 \mu \mathrm{g} \mathrm{mL}^{-1}$ (Supplementary Fig. 17). To identify which kind of ROS played a critical role in our system, one broad dichlorofluorescein diacetate (DCFH-DA) ROS probe and specific ROS scavengers DMSO $(\bullet \mathrm{OH})$, superoxide dismutase $\left(\mathrm{SOD}, \mathrm{O}_{2}{ }^{-}\right)$, and $\mathrm{NaN}_{3}\left({ }^{1} \mathrm{O}_{2}\right)$ were used. As displayed in Supplementary Fig. 18, no obvious fluorescence change was observed upon adding $\mathrm{NaN}_{3}(11 \%)$, whereas the fluorescence intensity of DCFH-DA was diminished dramatically after treatment with DMSO (46\%) or SOD (40\%), indicating that the oxidative ability of $\mathrm{MnO}_{2} @ \mathrm{PtCo}$ nanoflowers primarily stemmed from $\cdot \mathrm{OH}$ and $\mathrm{O}_{2}{ }^{\bullet-}$. Furthermore, only $\sim 5 \%$ of fluorescence intensity remained after subtracting the fluorescence intensity of DCFH-DA generated by $\bullet \mathrm{OH}, \mathrm{O}_{2}{ }^{\bullet-}$, and ${ }^{1} \mathrm{O}_{2}$ from the total fluorescence intensity, indicating little amount of other reactive species presented in our system. Furthermore, under the hypoxic $\mathrm{H}_{2} \mathrm{O}_{2}$ condition, a remarkable amount of $\mathrm{O}_{2}^{\cdot-}$ and $\bullet \mathrm{OH}$ were detected by adding 
a

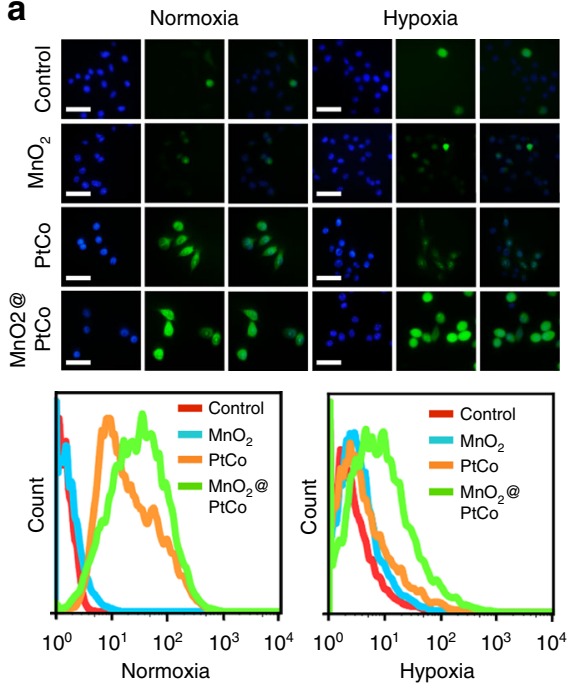

b
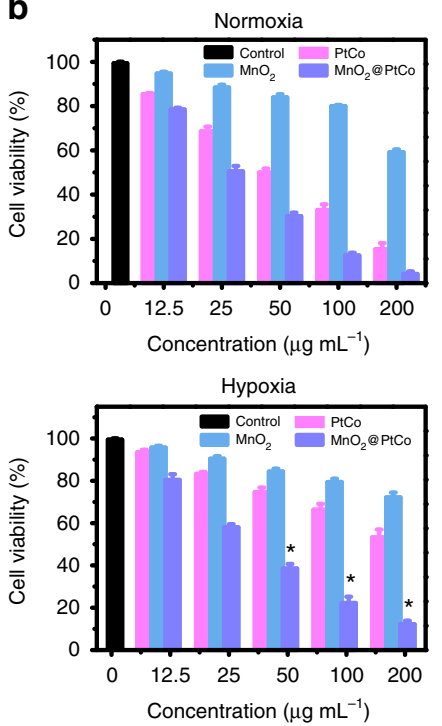

C
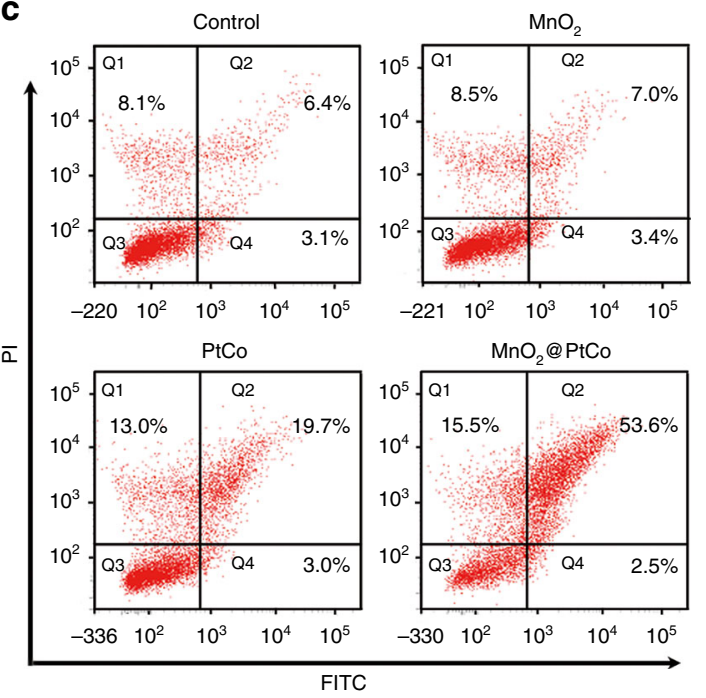

Fig. 4 In vitro assessments of $\mathrm{MnO}_{2} @ \mathrm{PtC}$ nanoflowers-induced intracellular oxidative damage. a Detection of MnO $\mathrm{M}_{2} @ \mathrm{PtCo}$ nanoflowers-induced ROS in 4T1 cells in normoxic and hypoxic culture media by fluorescence microscopy and flow cytometry, respectively. The left, middle and right images show DAPI (blue), DCFH-DA (green) and the merged images, respectively. The left, middle and right images show DAPI (blue), DCFH-DA (green) and the merged images, respectively. Scale bars are $50 \mu \mathrm{m}$. b Cell viability of $4 \mathrm{~T} 1$ cells treated with different concentrations of nanoparticles for $48 \mathrm{~h}$ in different $\mathrm{O}_{2}$ tensions. Asterisks indicate significant differences $\left({ }^{\star} P<0.01,{ }^{\star \star} P<0.005,{ }^{\star \star \star} P<0.001\right)$, analyzed by unpaired Student's two-sided $t$ test. Data were presented as mean \pm s.d. $(n=5)$. c Fluorescein-annexin $V$ and PI staining assays of $4 T 1$ cells treated with different formulations

$\mathrm{MnO}_{2} @ \mathrm{PtCo}$ nanoflowers (Fig. 3d, e). In comparison, no obvious signal of $\mathrm{O}_{2} \cdot{ }^{-}$and $\cdot \mathrm{OH}$ were detected in $\mathrm{MnO}_{2}$ and $\mathrm{PtCo}$ presented.

Since electron spin resonance (ESR) spectrum is considered as more direct evidence to identify $\operatorname{ROS}^{40}$, 5-tertbutoxycarbonyl-5methyl-1-pyrroline $\mathrm{N}$-oxide (BMPO) was employed as a trapping probe to further demonstrate the presence of $\mathrm{O}_{2}{ }^{--}$and $\bullet \mathrm{OH}$ in hypoxia. Notably, $\mathrm{BMPO} / \bullet \mathrm{OOH}$ and $\mathrm{BMPO} / \bullet \mathrm{OH}$ have overlapping ESR spectra ${ }^{41}$, thereby DMSO and SOD scavenger were used during measurement processes. As shown in Fig. 3f, $\mathrm{MnO}_{2} @$ PtCo nanoflowers induced the generation of a fourline spectrum with relative intensities of $1: 1: 1: 1$, which was the characteristic spectrum of $\mathrm{BMPO} / \bullet \mathrm{OOH}$. Furthermore, the characteristic spectrum of $\mathrm{BMPO} / \bullet \mathrm{OH}$ adduct showing a fourline spectrum of 1:2:2:1 intensity was also observed after $\mathrm{MnO}_{2} @ \mathrm{PtCo}$ nanoflowers treatment (Fig. 3g). These results validated that our nanoflowers have indeed the potential to generate $\mathrm{O}_{2} \cdot-$ and $\bullet \mathrm{OH}$ and their possibly catalytic mechanisms are provided in Supplementary Fig. 19.

We then investigated the ROS generation ability of $\mathrm{MnO}_{2} @ \mathrm{PtCo}$ nanoflowers in both normoxia and hypoxia. Upon increasing the levels of nanoflowers, the amount of generated ROS increased remarkably irrespective of $\mathrm{O}_{2}$ status (Supplementary Fig. 20a, d). Moreover, the ROS generating ability enhanced significantly when prolonging the reaction time (Supplementary Fig. 20b, c). Taken together, by engineering self-assembly of nanozymes, our well-designed nanoflowers could generate ROS efficiently in both normoxia and hypoxia without any external stimulus, transcending traditional ROS-mediated treatment paradigms.

In vitro cytotoxicity of $\mathrm{MnO}_{2} @ P t C o$ nanoflowers. Compared with $4 \mathrm{~T} 1$ cells incubated at $37^{\circ} \mathrm{C}$, the amount of $\mathrm{MnO}_{2} @ \mathrm{PtCo}$ nanoflowers inside cells incubated at $4^{\circ} \mathrm{C}$ was obviously decreased, implying that these nanoflowers entered cells mainly through energy-dependent endocytosis (Supplementary Fig. 21).
Moreover, the co-localization studies showed that the nanoflowers were mainly accumulated in acidic lysosomes, which was beneficial to improving oxidative capacity of nanoflowers (Supplementary Fig. 22). To evaluate intracellular ROS-generated capacity of nanoflowers, flow cytometry and fluorescence microscopy assays were carried out by utilizing DCFH-DA probe. As presented in Fig. 4a, both PtCo and $\mathrm{MnO}_{2} @ \mathrm{PtCo}$ treated cells exhibited bright green fluorescence in normoxia, but only obvious fluorescence was observed for the cells incubated with $\mathrm{MnO}_{2} @$ PtCo under hypoxia, confirming our nanoflowers could overcome the hypoxic environment to generate ROS efficiently.

Having proved the ROS generation ability of $\mathrm{MnO}_{2} @ \mathrm{PtCo}$ nanoflowers, their potential cytotoxicity under different $\mathrm{O}_{2}$ tensions was evaluated. As illustrated in Fig. 4b, MnO $@$ @tCo nanoflowers treatment offered obvious cancer cell killing in both normoxia and hypoxia because of efficient generation of ROS. Comparatively, PtCo nanozymes exhibited significant cytototoxicy in normoxia, but no obvious cell death was observed in hypoxia. Similar trends were also obtained from the LIVE (green)/DEAD (red) kit (Supplementary Fig. 23). These results indicated that $\mathrm{MnO}_{2} @ \mathrm{PtCo}$ nanoflowers could modulate intracellular biochemical reactions to induce cell death, irrespective of $\mathrm{O}_{2}$ status. Furthermore, fluorescein-annexin $\mathrm{V}$ and propidium iodide (PI) staining assays identified that the cell toxicity of $\mathrm{MnO}_{2} @$ PtCo nanoflowers in hypoxia were mainly associated with apoptosis (Fig. 4c). Owning to the $\mathrm{pH}$-dependent catalytic functions of nanozymes and different redox states between cancer and normal cells, $\mathrm{MnO}_{2} @$ PtCo nanoflowers have little cytotoxicity towards normal NIH 3T3 cells in both normaxic and hypoxic environments (Supplementary Fig. 24).

To demonstrate the merits of our nanoflowers in generating ROS, one conventional photosensitizer methylene blue (MB) was utilized to make a preliminary comparison. For ROS generation, MB exhibited a higher ROS generation ability after light irradiation than $\mathrm{MnO}_{2} @$ PtCo nanoflowers in normoxia, whereas in hypoxic $\mathrm{H}_{2} \mathrm{O}_{2}$ conditions, the nanoflowers showed much higher ROS generation ability than MB (Supplementary Fig. 25a), 


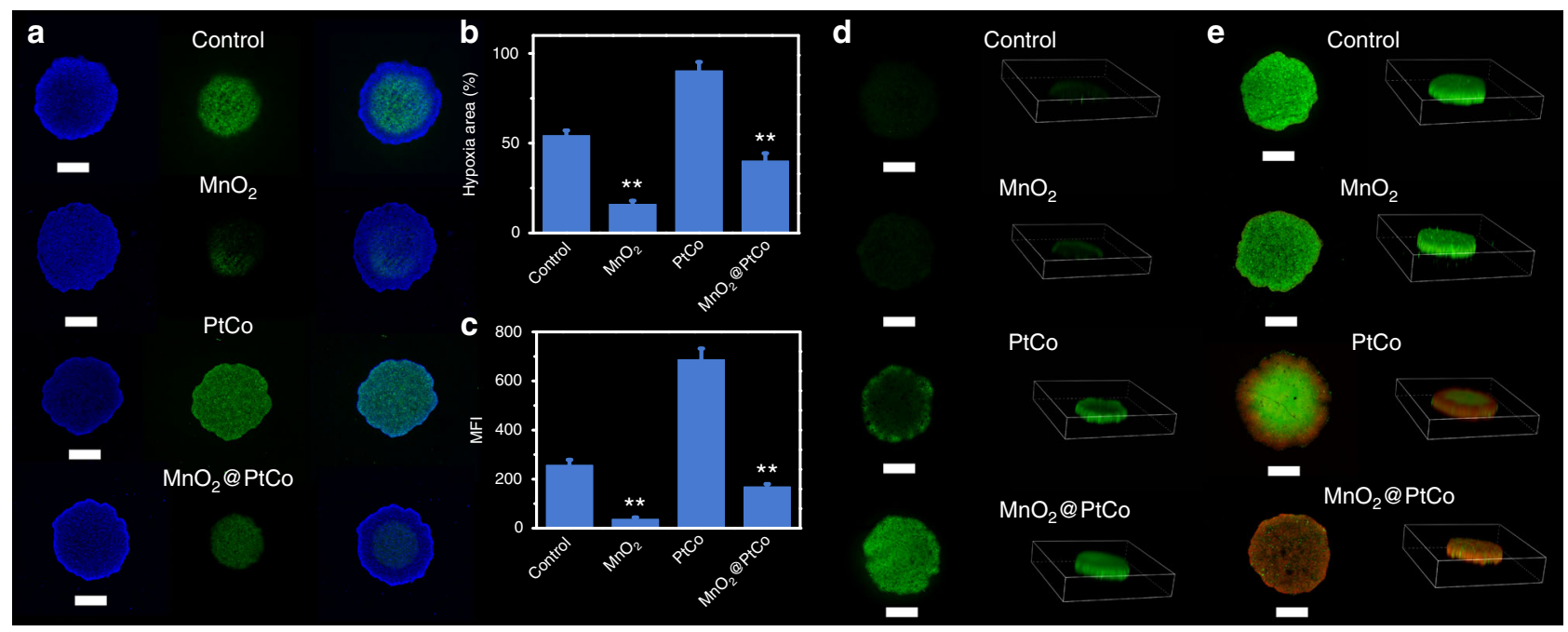

Fig. 5 The ability of $\mathrm{MnO}_{2} @$ PtCo nanoflowers on mitigating hypoxia, generating ROS and cytotoxicity in MCTS. a The hypoxia evaluation of 4 T1 MCTS at $24 \mathrm{~h}$ after various treatments. Hypoxia was assessed by staining with HIF-1 $\alpha$ (green) and DAPI (blue). b The quantification of hypoxia areas was performed with Image J. c Flow cytometric analysis of fluorescence intensity of HIF-1 $\alpha$ in MCTS after various treatments. d Detection of nanozymes-induced ROS in MCTS. e LIVE/DEAD staining of MCTS with Calcein-AM (green) and PI (red) at $24 \mathrm{~h}$ after different treatments. Scale bars are $500 \mu \mathrm{m}$. Asterisks indicate significant differences $\left({ }^{\star} P<0.01,{ }^{\star \star} P<0.005,{ }^{\star \star \star} P<0.001\right)$, analyzed by unpaired Student's two-sided $t$ test. Data were presented as mean \pm s.d. $(n=5)$

which could be attributed to the self-supplying $\mathrm{O}_{2}$ capacity of nanoflowers by catalyzing $\mathrm{H}_{2} \mathrm{O}_{2}$. Subsequently, we compared their toxicity against $4 \mathrm{~T} 1$ cells in different $\mathrm{O}_{2}$ tensions. Intriguingly, the cell viability induced by $\mathrm{MnO}_{2} @ \mathrm{PtCo}$ nanoflowers was comparable to $\mathrm{MB}$ treatment in normoxic tension (Supplementary Fig. 25b), which may be attributed to different ROS generation modes, where MB was mainly through a burst generation of ROS under light irradiation, whereas the continuous generation of ROS was demonstrated for $\mathrm{MnO}_{2} @ \mathrm{PtCo}$ nanoflowers without any external stimuli. Moreover, with selfsupplied $\mathrm{O}_{2}$ ability and continuous generation of ROS, $\mathrm{MnO}_{2} @ \mathrm{PtCo}$ nanoflowers showed significant toxicity towards 4T1 cells in hypoxic tension while MB not. To further demonstrate the advantages of our nanoflowers, pork tissues with $4 \mathrm{~mm}$ thickness were placed on the top of cell incubation plate. We found that the cell toxicity of $\mathrm{MB}$ was diminished dramatically upon light irradiation in both normoxia and hypoxia due to the limited light penetration depth, whereas negligible change was observed for nanoflowers treatment (Supplementary Fig. 25c). Taken together, such chemical generation of ROS taken from biological milieu by nanozymes in a noninvasive manner not only exhibited efficient cancer treatment, but also overcame the limitations of PDT.

Catalytic therapy effect in multicellular tumor spheroids. Since multicellular tumor spheroids (MTCS) could accurately replicate the heterogeneity of tumor microenvironment with a hypoxic core and normoxic surface ${ }^{42,43}$, we then embarked on constructing 4T1 MCTS to investigate the effect of $\mathrm{MnO}_{2} @ P t C o$ nanoflowers on mitigating hypoxia by employing hypoxia inducible factor (HIF)-1a staining assay. There was nearly no green fluorescence was detected in the internal area after $24 \mathrm{~h}$ incubation with $\mathrm{MnO}_{2}$ nanozyme (Fig. 5a), implying that it could effectively alleviate the hypoxia of MTCS. Comparatively, for PtCo nanozyme, green signals could be clearly seen both in the internal and edge of MCTS due to the continuous $\mathrm{O}_{2}$ consumption. Benefiting from reoxygenation capacity of $\mathrm{MnO}_{2}$ naozyme, the hypoxia area induced by $\mathrm{MnO}_{2} @ \mathrm{PtCo}$ nanoflowers was dramatically decreased to below $40 \%$ compared to PtCo nanozyme (Fig. 5b). To quantitatively evaluate the nanoflowers' ability in lessening hypoxia, flow cytometry analysis was carried out. As displayed in Fig. 5c, MCTS treated with $\mathrm{MnO}_{2} @ \mathrm{PtCo}$ nanoflowers exhibited much lower HIF-1a expression than control group, which was in favor for nanoflowers' oxidative cascade reactions in vivo. With such appealing properties, ROS generation capacity of $\mathrm{MnO}_{2} @$ PtCo nanoflowers in MTCS was determined. For PtCo treatment, green fluorescence was observed only at MCTS surface, whereas fluorescence signal in $\mathrm{MnO}_{2} @ \mathrm{PtCo}$ group was stronger and distributed throughout the entire MCTS (Fig. 5d). Subsequently, we further performed LIVE/DEAD assay of MCTS. After MCTS treated with $\mathrm{MnO}_{2} @ P t C o$ nanoflowers for $24 \mathrm{~h}$, almost all cells in MCTS were destroyed, while the damaged cells were only observed in the edge of MTCS for PtCo nanozyme group due to the inability to overcome the intrinsic hypoxic environment of MTCS (Fig. 5e). These results suggested that our designed $\mathrm{MnO}_{2} @ \mathrm{PtCo}$ nanoflowers could initiate intracellular biochemical reactions to alleviate the hypoxic microenvironment of MCTS, generate ROS and ultimately induce their death.

Cell death mechanism induced by $\mathrm{MnO}_{2} @ P t C o$ nanoflowers. To investigate whether cell apoptosis caused by $\mathrm{MnO}_{2} @ \mathrm{PtCo}$ nanoflowers in hypoxia was through ROS-mediated mechanism, the lipid peroxidation, DNA damage, lysosomes and mitochondrial disruption experiments were conducted. Firstly, thiobarbituric acid (TBA) assay was employed to evaluate lipid peroxidation after different treatments ${ }^{44}$. Compared with untreated control group, the levels of malondialdehyde (MDA) was increased by nearly $400 \%$ after exposure to $\mathrm{MnO}_{2} @ \mathrm{PtCo}$ nanoflowers, indicative of noticeable lipid peroxidation (Fig. 6a). DNA damage caused by nanoflowers was also evaluated by immunofluorescence staining of $\gamma-\mathrm{H}_{2} \mathrm{AX}$, a marker of DNA double-breaks ${ }^{45}$. As shown in Fig. $6 \mathrm{~b}$, a remarkable DNA damage was observed for cells treated with $\mathrm{MnO}_{2} @ \mathrm{PtCo}$ nanoflowers. Furthermore, acridine orange ( $\mathrm{AO})$ was adopted as an indicator for monitoring the integrity of lysosomes ${ }^{46}$. The lysosomes treated with $\mathrm{MnO}_{2}$ and PtCo nanozymes emitted bright red fluorescence, while the red fluorescence was remarkably reduced when treated with $\mathrm{MnO}_{2} @$ PtCo nanoflowers (Fig. 6c), implying the disruption of lysosomal membranes. Subsequently, JC-1 staining was employed to test mitochondrial membrane potential 

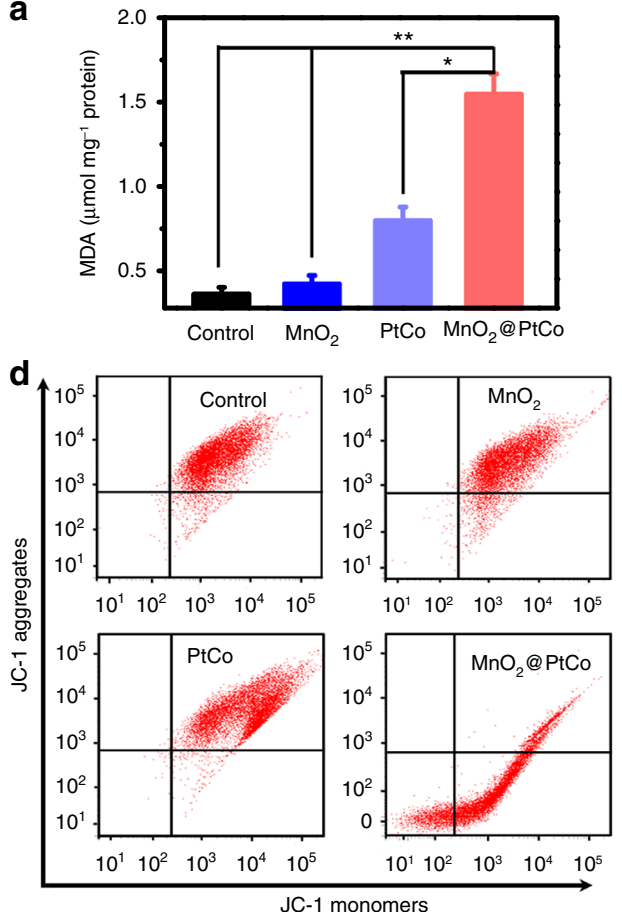

b

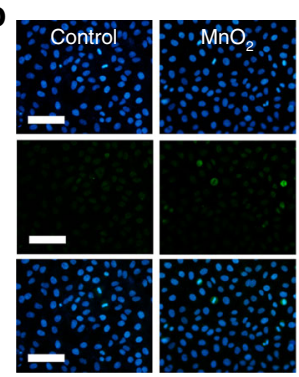

e

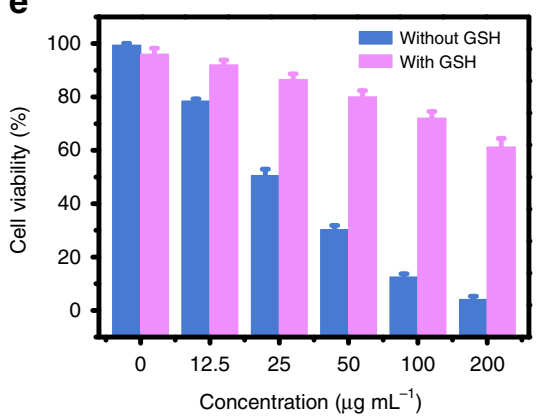

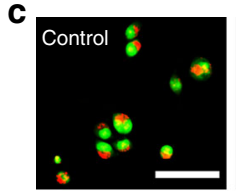
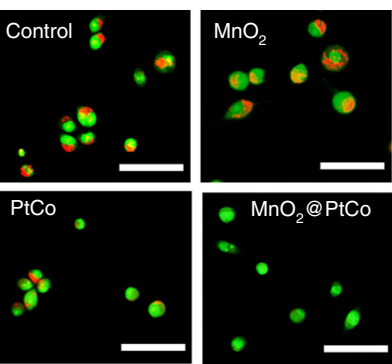

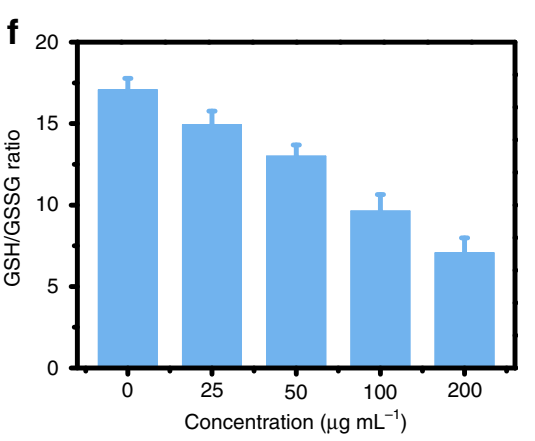

Fig. 6 Cell death mechanism caused by $\mathrm{MnO}_{2} @$ PtCo nanoflowers in hypoxic environment. a Changes of MDA content in 4T1 cells following treatment with different formulations. Asterisks indicate significantly differences $\left({ }^{\star} P<0.01,{ }^{\star \star} P<0.005,{ }^{\star \star \star} P<0.001\right)$, analyzed by unpaired Student's two-sided $t$ test. $\mathbf{b} \gamma-\mathrm{H}_{2} \mathrm{AX}$ foci immunofluorescence staining of $4 \mathrm{~T} 1$ cells incubated with various nanomaterials. The nucleus was stained with DAPI (blue) and $\gamma-\mathrm{H}_{2} \mathrm{AX}$ (green) was visualized by the FITC-labeled secondary antibody. Scale bars are $100 \mu \mathrm{m}$. c Fluorescence images of AO staining to evaluate lysosomal integrity of $4 \mathrm{~T} 1$ cells with different treatments. Scale bars are $200 \mu \mathrm{m}$. d JC-1 analysis of $4 \mathrm{~T} 1$ cells as a measure of mitochondrial depolarization

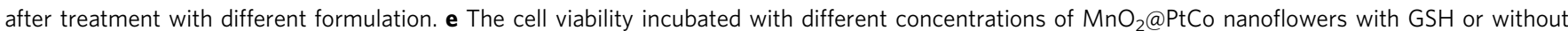
GSH added. $\mathbf{f G S H} / \mathrm{GSSH}$ ratios of $4 \mathrm{T1}$ cells treated with different concentrations of $\mathrm{MnO}_{2} @ \mathrm{PtC}$ nanoflowers. Data were presented as mean \pm s.d. ( $n=5$ )
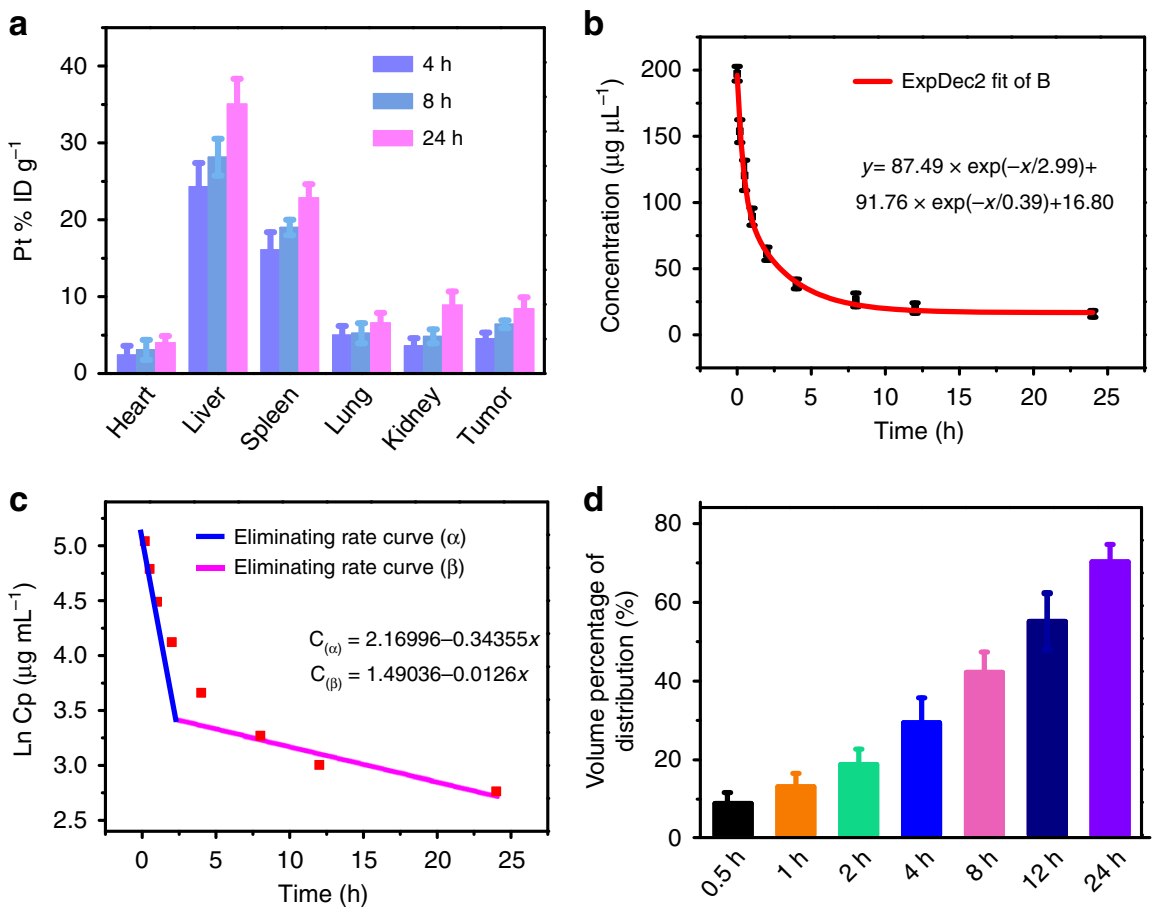

Fig. 7 The pharmacokinetics studies of $\mathrm{MnO}_{2} @$ PtCo nanoflowers. a The biodistribution of nanoflowers in main organs and tumors at different time points. b The blood circulation curve of intravenously injected nanoflowers. c The eliminating rate curve of nanoflowers from the blood circulation curve according to the $\operatorname{In}$ (concentration) $-T$ relationship. $\mathbf{d}$ The apparent volume percentage of distribution $\left(V_{d} \%\right)$ of intravenously injected nanoflowers. Data were presented as mean \pm s.d. $(n=3)$ 

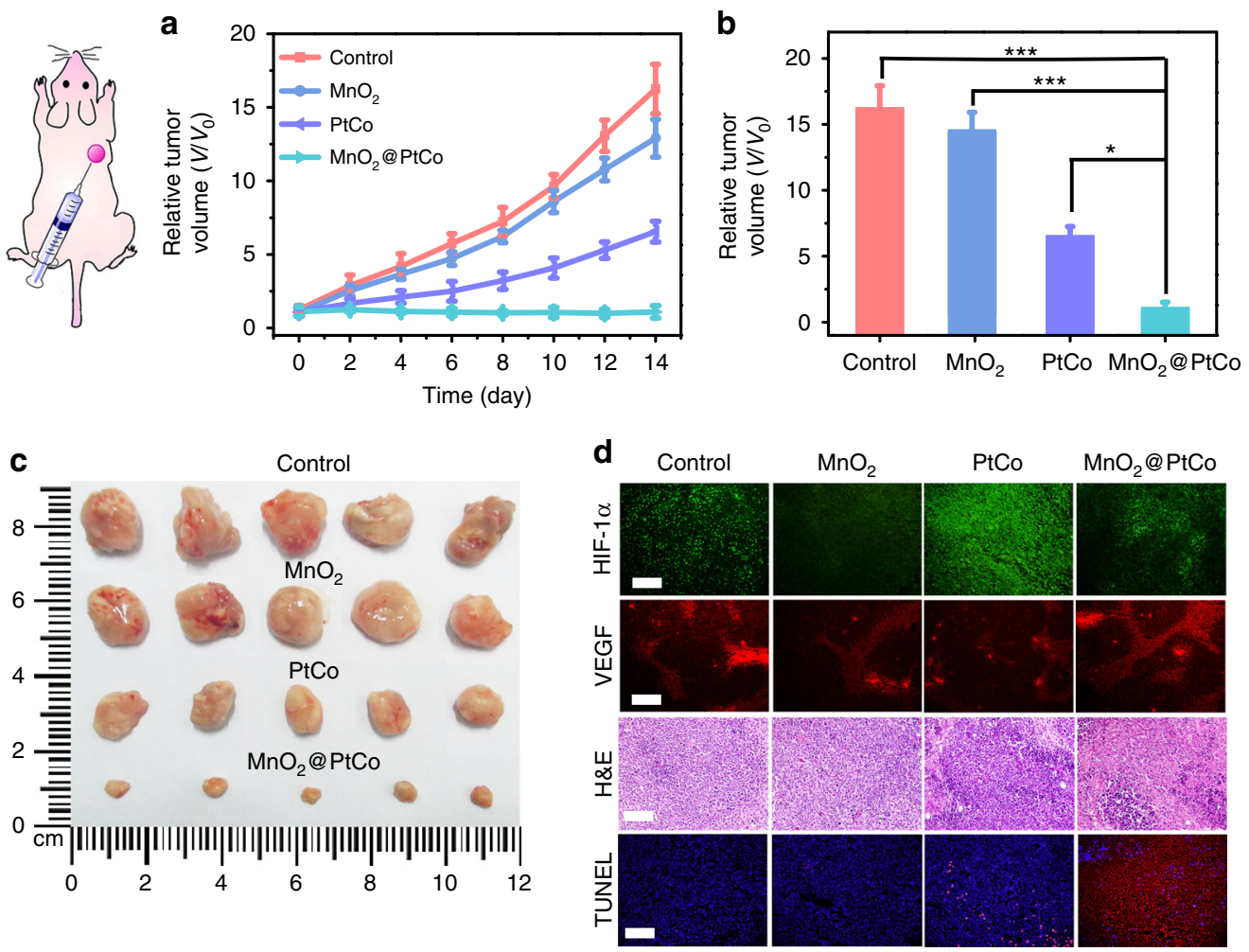

Fig. 8 In vivo therapeutic performance of $\mathrm{MnO}_{2} @ P t C o$ nanoflowers by intratumoral injection. a Time-dependent tumor volume changes after different treatments. b Comparison of inhibition effect of $\mathrm{MnO}_{2}, \mathrm{PtCo}$, and $\mathrm{MnO}_{2} @ \mathrm{PtC}$ on tumor growth after 14 days post injection. Asterisks indicate significant differences $\left({ }^{\star} P<0.01,{ }^{\star \star} P<0.005,{ }^{\star \star \star} P<0.001\right)$, analyzed by unpaired Student's two-sided $t$ test. $\mathbf{c}$ Photos of the tumors extracted from mice in different groups at the end of treatments (day 14). $\mathbf{d}$ Representative immunofluorescence images of tumor slices after hypoxia staining. The hypoxia positive areas and blood vessels were stained by HIF-1 $\alpha$ and VEGF, respectively. H\&E staining and TUNEL staining of tumor tissues at the 14th day. Nuclei were stained blue (DAPI staining), and apoptotic cells were stained red (TUNEL staining). Scale bars are $100 \mu \mathrm{m}$. Data were presented as mean \pm s.d. $(n=5)$

$(\mathrm{MMP})^{47}$. In Fig. 6d, $\mathrm{MnO}_{2} @$ PtCo nanoflowers led to the increase of red fluorescence aggregates and the decrease of green fluorescence monomer forms inside cells, suggesting the depolarization of mitochondrial membrane. Specially, the ratio of red/ green fluorescence intensity caused by $\mathrm{MnO}_{2} @ \mathrm{PtCo}$ was approximately three times higher than that of PtCo nanozymes (Supplementary Fig. 26). To further investigate the mechanism of cell death, the ROS scavenger GSH was employed. We discovered that cytotoxicity of $\mathrm{MnO}_{2} @$ PtCo nanoflowers was vanished upon exogenous addition of GSH (Fig. 6e). More interestingly, $\mathrm{MnO}_{2} @$ PtCo nanoflowers led to the obvious decrease of intracellular GSH/GSSH ratio, suggesting the imbalance of intracellular redox state (Fig. 6f). All above results demonstrated that $\mathrm{MnO}_{2} @ \mathrm{PtCo}$ nanoflowers could trigger cell apoptosis through ROS-mediated mechanism.

In vivo toxicology of $\mathrm{MnO}_{2} @ P t C o$ nanoflowers. In vivo toxicology of $\mathrm{MnO}_{2} @$ PtCo nanoflowers was investigated systematically to ensure their safe bioapplications. The liver status was reflected by the levels of alanine transaminase (ALT), aspartate transaminase (AST), alburnin (ALB), globulin (GLB), and total protein (TP), whilst kidney function was evaluated by measuring blood urea nitrogen (BUN) and creatinine (CREA) markers ${ }^{48}$. No significant difference between $\mathrm{MnO}_{2} @$ PtCo nanoflowers-treated groups and control group was observed at different time points (Supplementary Fig. 27a), elucidating that nanoflowers had little toxicity to liver and kidney. Since the potential risks of $\mathrm{MnO}_{2} @$ PtCo nanoflowers in inducing inflammatory responses would be reflected in hematological factors, the standard haemotology markers including red blood cells (RBC), hemoglobin
(HGB), hematocrit (HCT), mean corpuslar volume (MCV), mean corpuslar hemoglobin $(\mathrm{MCH})$, mean corpuslar hemoglobin concentration (MCHC), white blood cells (WBC, and platelets (PLT) were also measured. Compared with control group, all the blood indexes in the nanoflowers-treated groups were found to be normal, demonstrating no significant infection and inflammation were arose during the whole evaluation period. Besides, the injection of $\mathrm{MnO}_{2} @$ PtCo nanoflowers had negligible influence toward the mice growth (Supplementary Fig. 27b). Further hematoxylin and eosin (H\&E) staining assay of major organs including heart, liver, spleen, lung, and kidney proved the high histocompatibility of $\mathrm{MnO}_{2} @ P t C o$ nanoflowers (Supplementary Fig. 27c). These preliminary in vivo biosafety results indicated $\mathrm{MnO}_{2} @$ PtCo nanoflowers are nontoxic, which favors their further bioapplications.

The pharmacokinetics of $\mathrm{MnO}_{2} @$ PtCo nanoflowers. The pharmacokinetics of $\mathrm{MnO}_{2} @$ PtCo nanoflowers was evaluated to elucidate their behaviors in vivo. After systemic intravenous injection (i.v.), the biodistribution analysis of $\mathrm{MnO}_{2} @ \mathrm{PtCo}$ nanoflowers at different time points was initially studied. As illustrated in Fig. 7a, the nanoflowers were primarily accumulated in liver and spleen due to the capture of reticuloendothelial system. The relative distribution amounts of nanoflowers within tumor were $4.52 \%$ in $4 \mathrm{~h}$ and increased against time $(6.4 \%$, and $8.42 \%$ at time 8 and $24 \mathrm{~h}$, respectively), validating that $\mathrm{MnO}_{2} @$ PtCo nanoflowers could accumulated at tumor sites by EPR effect. According to blood circulation curve (Fig. 7b), the blood circulation of $\mathrm{MnO}_{2} @$ PtCo nanoflowers was followed a two-compartment model and their circulating half-life was 
calculated to be $0.86 \mathrm{~h}$, higher than conventional naked nanoparticles $(0.33 \mathrm{~h})^{49}$. Furthermore, based on the In(concentration) $-T$ relationship, we calculated that the eliminating curve constants of $\mathrm{MnO}_{2} @ P t C o$ nanoflowers were $-0.34355 \mu \mathrm{g} \mathrm{mL}-1 \mathrm{~h}$ ${ }^{-1}$ in the first stage and then decreased to $0.0126 \mu \mathrm{g} \mathrm{mL}^{-1} \mathrm{~h}^{-1}$ in the second state (Fig. 7c). The apparent volume percentage of distribution of nanoflowers exhibited increasing distribution kinetics in the whole blood of body (Fig. 7d). Collectively, these data indicated that $\mathrm{MnO}_{2} @ \mathrm{PtCo}$ nanoflowers exhibited a superior blood circulation profile.

In vivo tumor therapeutics of $\mathrm{MnO}_{2} @$ PtCo nanoflowers. Inspired by the potency of $\mathrm{MnO}_{2} @$ PtCo nanoflowers in vitro and the high biocompatibility in vivo, their therapeutic efficacy in vivo was first evaluated in 4T1 tumor-bearing mice via direct intratumoral injections. Twenty-eight tumor-bear mice were randomly divided into four groups, including control, $\mathrm{MnO}_{2}, \mathrm{PtCo}$, and $\mathrm{MnO}_{2} @$ PtCo. The tumor sizes of each group were measured by a caliper every other day. As presented in Fig. 8a, PtCo nanozymes exhibited certain therapeutic outcome, but failed to inhibit the growth of tumors, presumably due to the hypoxic environment of tumors ${ }^{39}$. Comparatively, $\mathrm{MnO}_{2} @ \mathrm{PtCo}$ nanoflowers exhibited admirable antitumor potentials (Fig. 8b), in which the tumors were almost completely removed (Fig. 8c). These results could be ascribed to the cooperation between oxidative activity of PtCo and supply $\mathrm{O}_{2}$ ability of $\mathrm{MnO}_{2}$ components. To demonstrate the ability of $\mathrm{MnO}_{2}$ to ameliorate hypoxia inside tumor, HIF-1 $\alpha$ and vascular endothelial growth factor (VEGF) staining assay were performed (Fig. 8d) ${ }^{50} \cdot \mathrm{MnO}_{2}$ led to remarkable downregulation of HIF-1a, indicating tumor hypoxia was successfully relieved. However, an enhanced HIF-1a expression was observed for PtCo-treated tumor tissues, implying that PtCo worsened hypoxia in tumor. Comparatively, after $\mathrm{MnO}_{2} @$ PtCo treatment, slight downregulation of HIF-1a was presented without affecting blood vessel densities, indicating the feasibility of our design. To further gain insight into the cytotoxic effect of nanoflowers, the tumor tissues were retrieved and processed for H\&E and terminal deoxynucleotidyl transferase dUTP nick-end labeling (TUNEL) analysis. $\mathrm{MnO}_{2} @ \mathrm{PtCo}$ nanoflowers could substantially reduce the number of tumor cells and increase the population of apoptotic cells than those control groups (Fig. 8d), indicating their capacity to inhibit tumor growth. Moreover, all the mice demonstrated negligible weight fluctuations and no obvious pathological change or other adverse effect was observed in organ tissues as compared with untreated group (Supplementary Fig. 28).

Since the different $\mathrm{pH}$ values between tumor tissues and normal organs as well as cancer cells are more vulnerable than normal cells to exogenous ROS, the higher and $\mathrm{pH}$-dependent catalytic ability of $\mathrm{MnO}_{2} @$ PtCo nanoflowers in modulating intracellular biochemical reactions bestow a chance to specifically suppress the growth of tumors. To prove this, we embarked on exploring the therapeutic efficacy of nanoflowers by i.v. Before that, we first studied whether $\mathrm{MnO}_{2} @$ PtCo nanoflowers were capable of mitigating tumor hypoxia after i.v. injection. As illustrated in Fig. 9a, with the assistance of $\mathrm{MnO}_{2}$ nanozyme, $\mathrm{MnO}_{2} @ \mathrm{PtCo}$ nanoflowers successfully promoted tumor oxygenation and undermine hypoxia compared to PtCo nanozymes, which was consistent with the results of intratumoral administration. On tumor suppression evaluation, the mice receiving $\mathrm{MnO}_{2} @ \mathrm{PtCo}$ nanoflowers treatment showed remarkable inhibition effect, to a level much more effective than that of mice receiving PtCo nanozymes (Fig. 9b, c). After the therapeutic process, tumors of mice were dissected and weighted (Fig. 9d, e). These results indicated that the tumors treated with nanoflowers were almost removed, further validating their outstanding therapeutic outcome. Furthermore, H\&E and TUNEL staining assays of tumors tissues further demonstrated that $\mathrm{MnO}_{2} @ \mathrm{PtCo}$ nanoflowers caused serious apoptosis of tumor cells (Fig. 9f). Notably, negligible weight fluctuations and abnormality in the major organs of mice were observed during the whole therapeutic period (Supplementary Fig. 29), demonstrating the catalytic ability of nanoflowers was specific for tumor tissues.

\section{Discussion}

We have developed a ROS generation platform based on selfassembled $\mathrm{MnO}_{2} @$ PtCo nanoflowers to initiate intracellular biochemical reactions against hypoxic tumors. Compared with traditional ROS-generating systems, our platform offers a number of advantages as follows. (1) The generation of ROS was through biochemical reactions occurred in biological milieu, in which no external activation was needed, thus alleviating the problems of current ROS-mediated treatment modalities such as light penetration depth, ultrasound-induced hyperthermia, and sophisticated instruments. (2) By the cooperation between the oxidative activity of PtCo and the supply $\mathrm{O}_{2}$ ability of $\mathrm{MnO}_{2}$ components, our $\mathrm{MnO}_{2} @$ PtCo nanoflowers were capable of relieving hypoxic condition and generating ROS efficiently in hypoxic tumors, thereby resulting in remarkable therapeutic outcome. (3) Based on cancer cells are more vulnerable to exogenous ROS than normal cells and the oxidative ability of $\mathrm{MnO}_{2} @ P t C o$ nanoflowers rely on the acidic $\mathrm{pH}$ (2.5-6.8), our nanoflowers could preferentially induce tumors apoptosis whereas show negligible side effect to major organs. Taken together, we expect that our approach of exploiting nanozymes assemblies as ROS source to induce cell apoptosis can open up an exciting research direction for designing and developing nanozymes to mimic intracellular enzyme for regulating cell functions such as migration, differentiation, gene expression, and so on.

\section{Methods}

Materials. Platinum (II) acetylacetonate ( $\left.\mathrm{Pt}(\mathrm{acac})_{2}\right)$, $\mathrm{Pt} 48 \%$ was purchased from Alfa Aesar. Cobalt (II) acetylacetonate $\left(\mathrm{Co}(\mathrm{acac})_{2}\right)$ was purchased from Adamas reagent. Poly(vinylpyrrolidone) $(\mathrm{PVP}, \mathrm{Mw}=8000)$ and 3,3,5,5-tetra-

methylbenzidine (TMB) were purchased from Aladdin Reagent. Benzoic acid was obtained from Macklin (Shanghai, China). 2-( $N$-morpholino)ethanesulfonic acid (MES) was purchased from Shanghai Sangon Biological Engineering Technology \& Services (Shanghai, China). Potassium permanganate $\left(\mathrm{KMnO}_{4}\right)$ and benzyl alcohol were purchased from Beijing Chemicals (Beijing, China). 2',7'-Dichlorofuorescein diacetate (DCFH-DA), Lipid Peroxidation MDA Assay Kit, mouse monoclonal HIF-1a (clone: H1a67, catalog: AH339, 1:200), and Rabbit polyclonal anti-VEGF (catalog: AV202, 1:200) were purchased from Beyotime Biotechnology. Rabbit antiPhospho-Histone $\mathrm{H}_{2} \mathrm{AX}$ (catalog: bs-3185R, 1:200) was purchased from Bioss. All chemicals were used as received from the suppliers without further purification. Ultrapure water (18.2 M $\Omega$; Millpore Co., USA) was used throughout the experiment.

Instruments. TEM images were recorded using a FEI TECNAI G2 20 HRTEM operating at $200 \mathrm{kV}$. XPS measurement was performed on an ESCALAB-MKII spectrometer (VG Co., United Kingdom) with $\mathrm{Al} \mathrm{Ka} \mathrm{X-ray} \mathrm{radiation} \mathrm{as} \mathrm{the} \mathrm{X-ray}$ source for excitation. XRD measurements were performed on a Bruker D8 FOCUS using $\mathrm{Cu} \mathrm{Ka}$ radiation. Ultraviolet-visible (UV-vis) spectroscopy assay was recorded with a JASCO-V550 spectrometer. Fluorescence measurements were carried out using a JASCO FP-6500 spectrofluorometer with the slit width for the excitation and emission of $3 \mathrm{~nm}$.

Synthesis of PtCo nanozyme. The bimetallic PtCo nanoparticles were prepared through a one-pot strategy. The optimization composition of Pt/Co (3:1) with the highest oxidase-like activity was used in our work. Briefly, $\mathrm{Pt}(\mathrm{acac})_{2}(16 \mathrm{mg})$, Co $(\mathrm{acac})_{2}(10.2 \mathrm{mg})$, benzoic acid $(50 \mathrm{mg})$, and PVP $(80 \mathrm{mg})$ were dispersed in $5 \mathrm{~mL}$ of benzyl alcohol and stirred for $15 \mathrm{~min}$. Subsequently, the resultant mixture was transferred into a $10 \mathrm{~mL}$ Teflon-lined stainless-steel autoclave at $180^{\circ} \mathrm{C}$ for $12 \mathrm{~h}$. The PtCo nanoparticles products were precipitated by acetone and washed with ethanol-acetone mixture three times, and redispersed in $2 \mathrm{~mL}$ of deionized water as stock solution. 


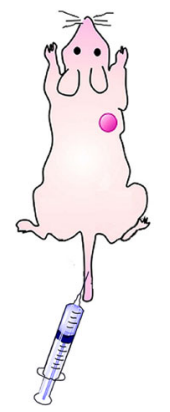

a
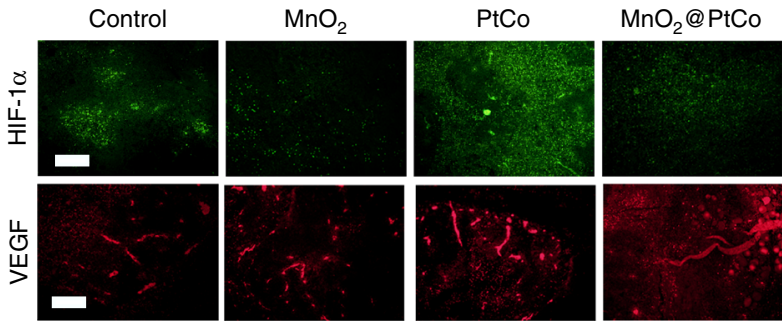

C

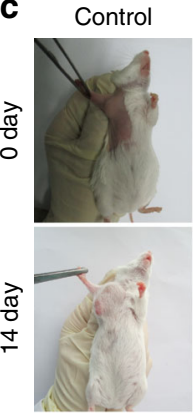

$\mathrm{MnO}_{2}$
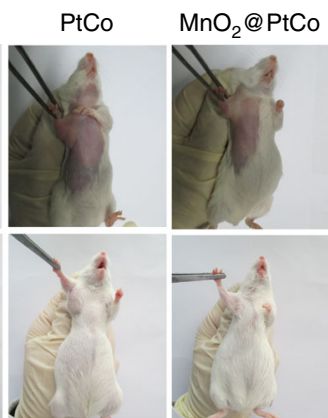

d

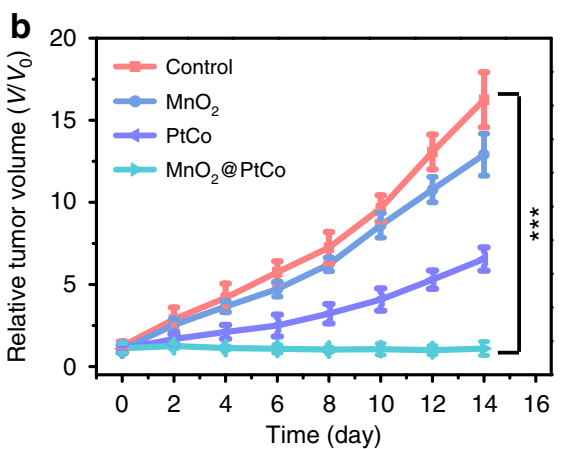

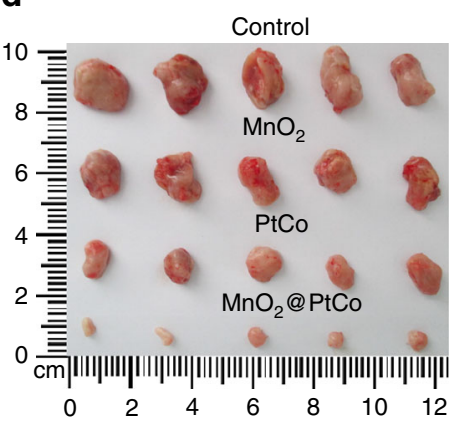

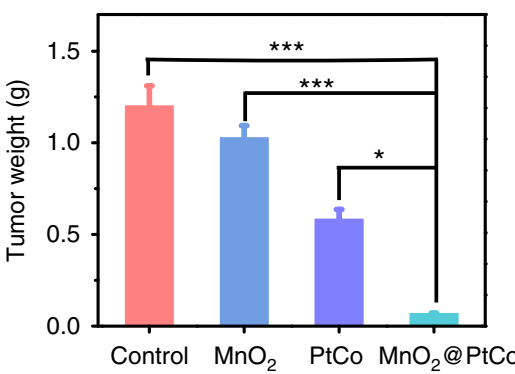

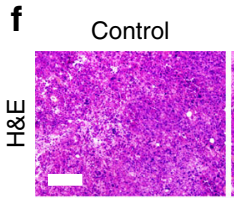
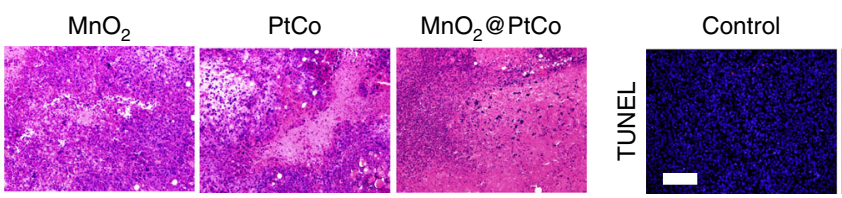

$\mathrm{MnO}_{2}$
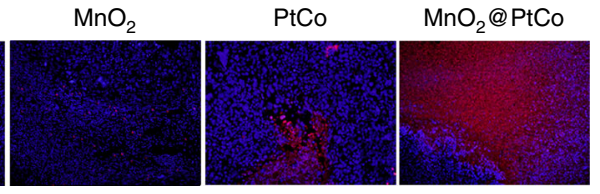

Fig. 9 In vivo therapeutic performance of $\mathrm{MnO}_{2} @ \mathrm{PtC}$ nanoflowers by intravenous injection. a After $24 \mathrm{~h}$ of various nanomaterials treatments, representative immunofluorescence images of tumor slices with HIF- $1 \alpha$ and VEGF staining. Scale bars are $100 \mu \mathrm{m}$. b Changes in tumor volumes used to evaluate the effectiveness of various treatments (i.v.) on treating tumor-bearing mice. c Photographs of the $4 \mathrm{~T} 1$ tumor-bearing mice before treatment and after 14 days post injection. $\mathbf{d}$ Photos of the dissected tumors after 14 days of treatment. $\mathbf{e}$ The weight of the dissected tumors after 14 days of treatment. f H\&E and TUNEL staining of tumor tissues at the 14th day. Scale bars are $100 \mu \mathrm{m}$. Asterisks indicate significant differences $\left({ }^{\star} P<0.01,{ }^{\star \star} P<0.005,{ }^{\star \star \star} P<\right.$ 0.001), analyzed by unpaired Student's two-sided $t$ test. Data were presented as mean \pm s.d. $(n=5)$

Preparation of $\mathbf{M n O}_{2} @$ PtCo nanoflowers. $\mathrm{MnO}_{2} @ \mathrm{PtCo}$ nanoflowers were synthesized as follows. Briefly, the stock solution $(20 \mu \mathrm{L}, 50 \mu \mathrm{L}$, or $100 \mu \mathrm{L})$ of PtCo nanoparticles was respectively added to a $1.5-\mathrm{mL}$ Eppendorf microtube (EP tube) containing $250 \mu \mathrm{L}$ of MES buffer (0.1 M, pH 6.0). Different amounts of $\mathrm{KMnO}_{4}$ $(10 \mathrm{mM}, 0-200 \mu \mathrm{L}$, namely, $0,50 \mu \mathrm{L}, 100 \mu \mathrm{L}, 150 \mu \mathrm{L}$, and $200 \mu \mathrm{L})$ was added to the EP tube. The resultant homogeneous solution was sonicated for 30 min until the solution became brown. Subsequently, $\mathrm{MnO}_{2} @ \mathrm{PtCo}$ nanomaterials were collected by centrifugation $(6000 \times g)$ and washed three times with deionized water. We found that using $100 \mu \mathrm{L}$ of PtCo nanozymes to direct the growth of $\mathrm{MnO}_{2}$ nanomaterials would lead to the products aggregation. The use of low concentrations of PtCo nanoparticles $(20 \mu \mathrm{L})$ exhibited a low catalytic activity. Incredibly, when the amount of PtCo used was $50 \mu \mathrm{L}$, the monodisperse spherical flowers structures of $\mathrm{MnO}_{2} @ \mathrm{PtCo}$ were prepared and exhibited the highest catalytic activity in our synthesized nanomaterials. Notably, the low concentrations of $\mathrm{KMnO}_{4}$ would lead to the lower field and catalytic performance. Therefore, $50 \mu \mathrm{L}$ of PtCo and $200 \mu \mathrm{L}$ of $\mathrm{KMnO}_{4}$ were used to prepare $\mathrm{MnO}_{2} @ \mathrm{PtCo}$ nanoflowers for subsequent in vitro and in vivo studies.

Oxidase-like activity of $\mathbf{M n O}_{2} @$ PtCo nanoflowers. The catalytic performance of $\mathrm{MnO}_{2} @$ PtCo nanoflowers for the oxidation of TMB was studied by monitoring the absorption spectra at $652 \mathrm{~nm}$ using a UV-vis spectrophotometer. In a typical test, $20 \mu \mathrm{g} \mathrm{mL}-1 \mathrm{MnO}_{2} @$ PtCo nanoflowers were suspended in $25 \mathrm{mM}$ of phosphate saline buffer (PBS) ( $\mathrm{pH}$ 5.0) and then TMB were added (final concentration $800 \mu \mathrm{M}$ ). To mimic a hypoxic condition, $\mathrm{N}_{2}$ gas was purged in PBS solution for 20 min to remove the dissolved $\mathrm{O}_{2}$ before adding $\mathrm{MnO}_{2} @$ PtCo nanoflowers.

Catalase (CAT)-mimic activity of $\mathbf{M n O}_{\mathbf{2}} @$ PtCo nanoflowers. Experiments were carried out using $20 \mu \mathrm{g} \mathrm{mL}-1 \mathrm{MnO}_{2} @ P t C o$ nanoflowers in a reaction volume of $1 \mathrm{~mL}$ PBS buffer ( $\mathrm{pH} \mathrm{5.0,6.8)} \mathrm{with} 20 \mathrm{mM} \mathrm{H}_{2} \mathrm{O}_{2}$ at $37^{\circ} \mathrm{C}$. After incubation of 10 min, the concentration of the consuming $\mathrm{H}_{2} \mathrm{O}_{2}$ was calculated according to the decrease of absorbance at $240 \mathrm{~nm}$.
Measurement of $\mathrm{O}_{2}$ production. The $\mathrm{O}_{2}$ concentrations in aqueous solutions were measured by a portable dissolved oxygen meter. For measurement of catalysis ability of $\mathrm{MnO}_{2}$ nanosheets, $\mathrm{H}_{2} \mathrm{O}_{2}$ was added to $30 \mathrm{~mL}$ of deoxygenated water and then the mixture was added in a $50 \mathrm{~mL}$ of three-neck flask that was closed by a rubber plug. The oxygen electrode probe was inserted through this rubber plug into the flask to measure the oxygen concentration of the solution in real time. When the $\mathrm{O}_{2}$ concentration of initial $\mathrm{H}_{2} \mathrm{O}_{2}$ solution reached equilibrium, $\mathrm{MnO}_{2}$ nanosheets and $\mathrm{H}_{2} \mathrm{O}_{2}$ were injected via a syringe into this closed system. The oxygen concentration was recorded in real time.

Detection of superoxide radical and hydroxyl radical. The detection of $\mathrm{O}_{2}{ }^{--}$was performed by taking the interaction between hydroethidine and DNA. In the presence of $\mathrm{O}_{2}{ }^{--}$, hydroethidine probe could be oxidized into ethidine which could intercalate into DNA and emit a bright red fluorescence. The determination of - $\mathrm{OH}$ was based on the reaction of between terephthalic acid (TA) and $\bullet \mathrm{OH}$. TA has negligible fluorescence by itself but is capable of capturing $\bullet \mathrm{OH}$ and generating 2hydroxy terephthalic acid with unique fluorescence around $435 \mathrm{~nm}$.

ESR measurements in hypoxia. For $\mathrm{O}_{2}{ }^{--}$detection, the pre-deoxidized PBS $(\mathrm{pH}$ 5.0, $25 \mathrm{mM}$ ) contained $25 \mathrm{mM}$ BMPO, $20 \mu \mathrm{g} \mathrm{mL}^{-1} \mathrm{MnO}_{2} @$ PtCo nanoflowers, $100 \mu \mathrm{M} \mathrm{H}_{2} \mathrm{O}_{2}, 50 \%$ DMSO was prepared. After incubation of $5 \mathrm{~min}$, ESR spectra were recorded. For $\bullet \mathrm{OH}$ detection, the pre-deoxidized PBS ( $\mathrm{pH} 5.0,25 \mathrm{mM}$ ) contained $25 \mathrm{mM} \mathrm{BMPO,} 20 \mu \mathrm{g} \mathrm{mL} \mathrm{MnO}_{2} @$ PtCo nanoflowers, $100 \mu \mathrm{M} \mathrm{H}_{2} \mathrm{O}_{2}$, $0.25 \mathrm{U} \mathrm{mL}^{-1}$ SOD was prepared. After incubation of $5 \mathrm{~min}$, ESR spectra were recorded. The following instrument settings were used for collecting ESR spectra: 1 $\mathrm{G}$ field modulation, $100 \mathrm{G}$ scan range, and $20 \mathrm{~mW}$ microwave power.

Cell culture in normoxic and hypoxic environments. Murine breast cancer 4T1 cell (ATCC-CRL-2539) and mouse embryonic fibroblast NIH 3T3 cell (ATCCCRL-1658) were purchased from China Center for Type Culture Collection. Both $4 \mathrm{~T} 1$ and NIH 3T3 cells were cultured with regular growth media contained with high glucose DMEM. The cell growth media was supplemented with $10 \%$ FBS, 
$100 \mathrm{U} \mathrm{mL}^{-1}$ penicillin, and $100 \mathrm{mg} \mathrm{mL}^{-1}$ streptomycin and cultured at $37^{\circ} \mathrm{C}$ in a $5 \% \mathrm{CO}_{2}$ for mimicking the normoxic environment. The media was changed every 2 days and the cells were digested by trypsin and re-suspended in fresh medium before confluence. In order to mimic the hypoxic tumor microenvironment, $4 \mathrm{~T} 1$ and NIH 3 T3 cells were cultured in a DMEM medium in an atmosphere of $1 \% \mathrm{O}_{2}$ and $5 \% \mathrm{CO}_{2}$ at $37^{\circ} \mathrm{C}$. Notably, throughout the studies, all cells were tested negative for mycoplasma contamination.

Cell internalization at $4^{\circ} \mathrm{C}$. Briefly, $4 \mathrm{~T} 1$ cells were randomly plated in six-well plates and allowed to adhere for $24 \mathrm{~h}$. After that, $\mathrm{MnO}_{2} @ \mathrm{PtCo}$ nanoflowers $\left(100 \mu \mathrm{g} \mathrm{mL}^{-1}\right)$ and PtCo nanoparticles $\left(100 \mu \mathrm{g} \mathrm{mL}^{-1}\right)$ were added into the six-well plates, respectively. Subsequently, the six-well plates were placed in $4^{\circ} \mathrm{C}$ refrigerator. After incubation at different times, the $4 \mathrm{~T} 1$ cells in six-well plates were washed with PBS three times and then harvested and treated with aqua regia for $8 \mathrm{~h}$ under heat treatment $\left(80^{\circ} \mathrm{C}\right)$ for dissolution of intracellular nanoparticles. The obtained liquid was subjected to ICP-MS analysis.

Determination of ROS generation in vitro. For ROS detection, $4 \mathrm{~T} 1$ cells were randomly seeded in six-well plates in DMEM for $24 \mathrm{~h}$ before further manipulation. Then cells were then incubated with $\mathrm{MnO}_{2}\left(100 \mu \mathrm{g} \mathrm{mL}^{-1}\right)$, PtCo nanozymes $\left(100 \mu \mathrm{g} \mathrm{mL}{ }^{-1}\right)$, and $\mathrm{MnO}_{2} @ \mathrm{PtCo}$ nanoflowers $\left(100 \mu \mathrm{g} \mathrm{mL}^{-1}\right)$ for $12 \mathrm{~h}$ under normoxic and hypoxic conditions, respectively. The treated cells were washed with PBS twice and incubated with $10 \mu \mathrm{M}$ of DCFH-DA for $30 \mathrm{~min}$. After the unloaded probe was removed with PBS, the fluorescence intensity of cells was monitored by flow cytometry and fluorescence microscopy.

In vitro cytotoxicity assay. MTT assay was used to determine the cytotoxicity of $\mathrm{MnO}_{2} @ \mathrm{PtCo}$ nanoflowers under normoxia and hypoxia. Briefly, 4T1 cells were randomly seeded into 96 -well plates at a density of 5000 cells per well $(100 \mu \mathrm{L})$, under $100 \%$ humidity and were cultured at $37^{\circ} \mathrm{C}$ with $5 \% \mathrm{CO}_{2}$ for $24 \mathrm{~h}$. Different concentrations of $\mathrm{MnO}_{2} @ \mathrm{PtCo}$ nanoflowers were added to the wells. The cells were subsequently incubated for $48 \mathrm{~h}$ in the $\mathrm{CO}_{2}$ incubator under normoxic and hypoxic conditions, respectively. Then, $10 \mu \mathrm{L}$ of MTT solution $\left(5 \mathrm{mg} \mathrm{mL}^{-1}\right)$ was added to each well to a final volume of $100 \mu \mathrm{L}$. After that, the plate was placed in the $\mathrm{CO}_{2}$ incubator for additional $4 \mathrm{~h}$. The media was removed and DMSO $(100 \mu \mathrm{L})$ was added into each well. Absorbance values were determined with Bio-Rad model-680 microplate reader at $490 \mathrm{~nm}$ (corrected for background absorbance at $630 \mathrm{~nm}$ ). The cell viability was estimated according to the following equation: Cell Viability $(\%)=$ $\left(\mathrm{OD}_{\text {Treated }} / \mathrm{OD}_{\text {Control }}\right) \times 100 \%$. Where $\mathrm{OD}_{\text {Control }}$ was obtained in the absence of nanoparticles, and $\mathrm{OD}_{\text {Treated }}$ was in the presence of nanoparticles.

Annexin V/PI assay. 4T1 cells were randomly plated in six-well plates and allowed to adhere for $24 \mathrm{~h}$ in a hypoxic environment $\left(1 \% \mathrm{O}_{2}\right)$. Then the cells were incubated with $\mathrm{MnO}_{2}\left(100 \mu \mathrm{g} \mathrm{mL} \mathrm{L}^{-1}\right)$, PtCo $\left(100 \mu \mathrm{gL}^{-1}\right)$, and $\mathrm{MnO}_{2} @ \mathrm{PtCo}$ nanoflowers $\left(100 \mu \mathrm{g} \mathrm{mL}^{-1}\right)$ for $24 \mathrm{~h}$. After that, the cells were stained with $5 \mu \mathrm{L}$ annexin V-FITC at room temperature for $15 \mathrm{~min}$ and followed by $10 \mu \mathrm{L}$ PI for 5 $\mathrm{min}$ in the dark. The fluorescence intensity of cells was viewed by flow cytometry in green channel for annexin V-FITC and red channel for PI, respectively.

MCTS experiments. The three-dimensional MCTS were constructed as follows. Briefly, $5 \times 10^{4} 4 \mathrm{~T} 1$ cells per well were seeded into a $1.5 \%(\mathrm{w} / \mathrm{v})$ agarose pre-coated 96-well plate and incubated at $37{ }^{\circ} \mathrm{C}$ in humidified atmosphere with $5 \% \mathrm{CO}_{2}$ for 10 days to form MCTS. The culture medium was replaced with fresh DMEM containing 10\% FBS every 2 days.

To demonstrate our system capable of alleviating hypoxic microenvironment, the MCTS were treated with PBS, $\mathrm{MnO}_{2}\left(100 \mu \mathrm{gL}^{-1}\right)$, PtCo $\left(100 \mu \mathrm{g} \mathrm{mL}^{-1}\right)$, and $\mathrm{MnO}_{2} @ \mathrm{PtCo}\left(100 \mu \mathrm{gL}^{-1}\right)$ for $24 \mathrm{~h}$, respectively. Afterwards, the immunofluorescence staining of HIF-1 $\alpha$ in treated MCTS was performed. Firstly, MCTS was fixed in $4 \%$ paraformaldehyde for $1 \mathrm{~h}$, and then treated with $0.5 \%$ Triton X-100 for $30 \mathrm{~min}$, followed by bovine serum albumin (BSA) was used to prevent other nonspecific protein interactions. Subsequently, the cells were incubated with HIF-1 $\alpha$ mouse monoclonal antibody $(1: 200)$ overnight at $4{ }^{\circ} \mathrm{C}$, and then the corresponding FITC-labeled sheep anti-mouse secondary antibody (1:500) was added for $2 \mathrm{~h}$ at $37^{\circ} \mathrm{C}$. Hoechst was used to stain the cell nuclei. Finally, the resultant MCTS was observed by confocal laser scanning microscope. The obtained images were collected at the center of each MCTS.

We also studied the ROS generation ability and toxicity of $\mathrm{MnO}_{2} @ \mathrm{PtCo}$ nanoflowers in MCTS. The MCTS were treated with PBS, $\mathrm{MnO}_{2}\left(100 \mu \mathrm{gL}^{-1}\right)$, PtCo $\left(100 \mu \mathrm{g} \mathrm{m}^{-1}\right)$, and $\mathrm{MnO}_{2} @ \mathrm{PtCo}\left(100 \mu \mathrm{g} \mathrm{mL}^{-1}\right)$ for $24 \mathrm{~h}$, respectively. Afterwards, the MCTS was fixed in $4 \%$ paraformaldehyde for $1 \mathrm{~h}$, and then incubated with DCFH-DA for $1 \mathrm{~h}$ to determine the ROS generation efficacy. Furthermore, after fixing the MCTS treated with different samples in $4 \%$ paraformaldehyde for $1 \mathrm{~h}$, they were stained with LIVE/DEAD Kit with $1 \mathrm{~h}$ to investigate their cytotoxicity.

Determination of lipid peroxidation. Lipid peroxidation was evaluated by measuring methane dicarboxylic aldehyde (MDA) production based on TBA reactivity. In a typical experiment, 4T1 cells were seeded in six-well plates and cultured in a hypoxic environment for $24 \mathrm{~h}$ and then the adherent cells were randomly incubated with $\mathrm{MnO}_{2}\left(100 \mu \mathrm{g} \mathrm{mL}^{-1}\right)$, PtCo $\left(100 \mu \mathrm{g} \mathrm{mL}^{-1}\right)$, and $\mathrm{MnO}_{2} @ \mathrm{PtCo}$ $\left(100 \mu \mathrm{g} \mathrm{mL}^{-1}\right)$ for $24 \mathrm{~h}$, respectively. After that, the adherent cells were harvested and treated according to the lipid peroxidation MDA Assay Kit.

DNA double-strand breaks under hypoxia. To test DNA double-strand breaks, $4 \mathrm{~T} 1$ cells were randomly seeded in a 24 -well plate and incubated in a hypoxic environment for $24 \mathrm{~h}$. Then different treatments including $\mathrm{MnO}_{2}(100 \mu \mathrm{g} \mathrm{mL}-1)$, PtCo $\left(100 \mu \mathrm{g} \mathrm{mL}^{-1}\right)$, and $\mathrm{MnO}_{2} @$ PtCo $\left(100 \mu \mathrm{g} \mathrm{mL}^{-1}\right)$ were added into the 24-well plate. After treatment for $24 \mathrm{~h}$, the immunofluorescence staining of $\gamma-\mathrm{H}_{2} \mathrm{AX}$ was conducted. Firstly, the cells were fixed with $4 \%$ paraformaldehyde for $30 \mathrm{~min}$ and subsequently $0.5 \%$ Triton X-100 was used to penetrate the cells for $5 \mathrm{~min}$, followed by BSA was used to prevent other nonspecific protein interactions. Finally, the cells were incubated with $\gamma-\mathrm{H}_{2} \mathrm{AX}$ antibody $(1: 200)$ overnight at $4{ }^{\circ} \mathrm{C}$ and then the corresponding FITC-labeled sheep anti-mouse secondary antibody (1:500) was added for $1 \mathrm{~h}$ at $37^{\circ} \mathrm{C}$. Excess antibody was removed by rinsing coverslips in PBS. Hoechst was used to stain the cell nuclei.

Analysis of lysosomal disruption. The ROS-induced lysosomal damage was tested using acridine organe ( $\mathrm{AO})$ as an indicator. $\mathrm{AO}$ emitted red fluorescence in acidic organelle such lysosomes while emitted green fluorescence in cytoplasm and nuclei. Typically, $4 \mathrm{~T} 1$ cells were randomly seeded in a 24 -well plate and incubated in a hypoxic environment for $24 \mathrm{~h}$. Subsequently, different groups including $\mathrm{MnO}_{2}$ $\left(100 \mu \mathrm{g} \mathrm{mL}^{-1}\right)$, PtCo $\left(100 \mu \mathrm{g} \mathrm{mL}^{-1}\right)$, and $\mathrm{MnO}_{2} @ \mathrm{PtCo}\left(100 \mu \mathrm{g} \mathrm{m}^{-1}\right)$ were added into the wells for incubation of $24 \mathrm{~h}$. Then, the cells were stained with AO $(5 \mu \mathrm{M})$ for $15 \mathrm{~min}$ and were washed twice with $1 \times$ PBS. Then cells were images immediately by fluorescence microscopy under excitation $488 \mathrm{~nm}$.

Analysis of MMP. 4T1 cells were randomly planted in six-well plates and allowed to adhere for $24 \mathrm{~h}$ in a hypoxic environment and the adherent cells were incubated with $\mathrm{MnO}_{2}\left(100 \mu \mathrm{g} \mathrm{mL}^{-1}\right)$, PtCo $\left(100 \mu \mathrm{gL}^{-1}\right)$, and $\mathrm{MnO}_{2} @$ PtCo $\left(100 \mu \mathrm{gL}^{-1}\right)$ for $24 \mathrm{~h}$, respectively. Then, the cells were harvested and treated with JC-1 $\left(5 \mu \mathrm{g} \mathrm{mL}^{-1}\right)$ at $37^{\circ} \mathrm{C}$ for $20 \mathrm{~min}$. The fluorescence intensity of the cells was measured by flow cytometry and fluorescence microscopy, respectively. Cells were viewed on fluorescence microscopy in red channel for J-aggregates and green channel for JC-1 monomer, respectively.

In vivo biocompatibility of $\mathbf{M n O}_{\mathbf{2}} @$ PtCo nanoflowers. Eight-week-old female $\mathrm{Balb} / \mathrm{c}$ mice were purchased form Laboratory Animal Center of Jilin University (Changchun, China) and all animal care and handing procedures were in accordance with the guidelines approved by the ethics committee of Jilin University. All study protocols involving animals were approved by the Jilin University Animal Care and Use Committee. Thirty healthy female Balb/c mice were randomly divided into three groups, including saline (control), $\mathrm{MnO}_{2}$ nanoflowers $\left(5 \mathrm{mg} \mathrm{kg}^{-1}, 7\right.$ days post injection), and $\mathrm{MnO}_{2}$ nanoflowers ( $5 \mathrm{mg} \mathrm{kg}^{-1}, 28$ days post injection). Aliquots $(50 \mu \mathrm{L})$ of saline and nanoflowers were intravenously administrated into mice of the corresponding group. The mice body weights were measured every 3 days to evaluate the in vivo biosafety. At the indicated time, the mice were euthanized and their blood samples were collected to perform complete blood panel analysis and serum biochemistry assay at the Jilin ADICON Clinical Laboratories, Inc. The major organs containing heart, liver, spleen, lung, and kidney were harvested, fixed in $10 \%$ paraformaldehyde, processed into paraffin, sectioned at $\sim 4 \mu \mathrm{m}$, and stained with $\mathrm{H} \& \mathrm{E}$

In vivo biodistirbution and pharmacokinetic of $\mathbf{M n O}_{\mathbf{2}} @ \mathbf{P t C o}$. In the quantitative biodistribution analysis, $4 \mathrm{~T} 1$ tumor-bearing mice were intravenously injected with $\mathrm{MnO}_{2} @$ PtCo nanoflowers $\left(50 \mu \mathrm{L}, 5 \mathrm{mg} \mathrm{kg}^{-1}\right)$ and randomly divided into three groups $(n=3)$. At $4 \mathrm{~h}, 8 \mathrm{~h}$, and $24 \mathrm{~h}$ post administration, the mice were sacrificed, and the tumor tissues and main organs containing heart, liver, spleen, lung, and kidney were excised and weighted, and then digested in aqua regia under heat treatment $\left(80^{\circ} \mathrm{C}\right)$ for 3 days to analyze the content of $\mathrm{Pt}^{2+}$ in the samples using ICP-MS

For in vivo pharmacokinetic evaluation, female Balb/c mice $(n=3)$ were i.v. injected with $\mathrm{MnO}_{2} @ \mathrm{PtCo}$ nanoflowers $\left(50 \mu \mathrm{L}, 5 \mathrm{mg} \mathrm{kg}^{-1}\right)$. At 5, 10, $30 \mathrm{~min}, 1,2,4$, $8,12 \mathrm{~h}$, and $24 \mathrm{~h}$ post injection, $10 \mu \mathrm{L}$ of blood were collected by puncturing the tail vein and dispersed into $990 \mu \mathrm{L}$ aqua regia to dissolve the remained $\mathrm{MnO}_{2} @ \mathrm{PtCo}$ nanoflowers. The concentrations of Pt ions were measured by ICP-MS. The in vivo circulating half-life of $\mathrm{MnO}_{2} @ \mathrm{PtCo}$ in blood stream $\left(\tau_{1 / 2}\right)$ is calculated by a doublecompartment pharmacokinetic model. The eliminating rate curve was conducted by plotting $\ln \left(C_{\mathrm{pt}}\right)$ against time and fitted according to the two-compartment models. The eliminating rates were reflected by the slopes of the curve.

Tumor model and $\mathrm{MnO}_{2} @$ PtCo nanoflowers treatment in vivo. To develop a tumor model, 4T1 cells $\left(1 \times 10^{6}\right)$ suspended in PBS were subcutaneously injected into the left flank mammary gland of each female Balb/c mouse. When the tumor volume reached $\approx 100 \mathrm{~mm}^{3}$, mice were divided randomly into four groups consisting of seven mice in each group. Then, mice received $50 \mu \mathrm{L}$ of the intratumoral and i.v. of PBS, $\mathrm{MnO}_{2}\left(5 \mathrm{mg} \mathrm{kg}^{-1}\right)$, PtCo $\left(5 \mathrm{mg} \mathrm{kg}^{-1}\right)$, and $\mathrm{MnO}_{2} @$ PtCo nanoflowers $\left(5 \mathrm{mg} \mathrm{kg}^{-1}\right)$, respectively. Subsequently, tumor growth was recorded by measuring the tumor's perpendicular diameter using a caliper estimated by 
employing the following equation: volume $=($ tumor length $) \times(\text { tumor width })^{2} / 2$. To ensure the accuracy of experiments, three individuals participated in the experiments. One was responsible for preparing nanozymes, selecting mice and handing them to the second researcher who performed the injections. The last researcher collected and analyzed results. So, investigators performing tumor measurements were blinded to treatment groups.

Immunofluorescence stainings of HIF-1 $\alpha$ and VEGF. 4T1 tumor-bearing mice were divided into four groups randomly, and subjected to the following treatments: group 1: PBS $(50 \mu \mathrm{L})$ only; group 2: $\mathrm{MnO}_{2}\left(50 \mu \mathrm{L}, 5 \mathrm{mg} \mathrm{kg}^{-1}\right)$; group 3: PtCo $\left(50 \mu \mathrm{L}, 5 \mathrm{mg} \mathrm{kg}^{-1}\right)$; group 4: $\mathrm{MnO}_{2} @ \mathrm{PtCo}$ nanoflowers $\left(50 \mu \mathrm{L}, 5 \mathrm{mg} \mathrm{kg}^{-1}\right)$. After $24 \mathrm{~h}$ post injection, the tumors of mice with a similar tumor volume in these four groups were collected and fixed in $10 \%$ paraformaldehyde, embedded in paraffin, sectioned into $\sim 4 \mu \mathrm{m}$ and treated with $0.5 \%$ Triton X-100 for $10 \mathrm{~min}$, followed by incubation of BSA for $30 \mathrm{~min}$. Then, the slices were incubated with HIF-1 $\alpha$ antibody (1:200) and VEGF antibody (1:200) overnight at $4{ }^{\circ} \mathrm{C}$, respectively. Subsequently, the corresponding secondary antibody (1:500) was added for $1 \mathrm{~h}$ at $37^{\circ} \mathrm{C}$. Excess antibody was removed by rinsing coverslips in PBS.

H\&E and TUNEL staining. For histology, major organs and tumors were harvested from mice at $48 \mathrm{~h}$ after injection. The collected tumors and organs were fixed in $10 \%$ paraformaldehyde, embedded in paraffin, sectioned into $\sim 4 \mu \mathrm{m}$, and stained with H\&E. In addition, for determining tumor cells apoptosis, tumor slices were stained with TUNEL according to One Step TUNEL Apoptosis Assay Kit (purchased from Beyotime Biotechnology). The histology was performed in college of Basic Medical Sciences of Jilin University. The samples were examined by an Olympus BX-51 microscope.

Statistical analysis. All data were expressed in this article as mean result \pm standard deviation (s.d.). All figures shown in this article were obtained from five independent experiments with similar results unless specific mention. The statistical analysis was performed by using Origin 8.0 software. Statistical evaluation was performed using unparied Student's two-sided $t$ test analysis. Asterisks indicate significant differences $\left({ }^{*} P<0.01,{ }^{* *} P<0.005,{ }^{* * *} P<0.001\right)$. Notably, no samples and animals were excluded from the analysis.

Data availability. All data are available from the authors on reasonable request.

Received: 20 February 2018 Accepted: 7 June 2018

Published online: 20 August 2018

\section{References}

1. Winterbourn, C. C. Reconciling the chemistry and biology of reactive oxygen species. Nat. Chem. Biol. 4, 278-286 (2008).

2. Zhou, Z., Song, J., Nie, L. \& Chen, X. Reactive oxygen species generating systems meeting challenges of photodynamic cancer therapy. Chem. Soc. Rev. 45, 6597-6626 (2016).

3. Schumacker, P. T. Reactive oxygen species in cancer cells: live by the sword, die by the sword. Cancer Cell 10, 175-176 (2006).

4. Trachootham, D., Alexandre, J. \& Huang, P. Targeting cancer cells by ROSmediated mechanisms: a radical therapeutic approach? Nat. Rev. Drug Discov. 8, 579-591 (2009).

5. Kong, Q., Beel, J. A. \& Lillehei, K. O. A threshold concept for cancer therapy. Med. Hypotheses 55, 29-35 (2000).

6. Pelicano, H., Carney, D. \& Huang, P. ROS stress in cancer cells and therapeutic implications. Drug Resist. Updat. 7, 97-110 (2004).

7. Lucky, S. S., Soo, K. C. \& Zhang, Y. Nanoparticles in photodynamic therapy. Chem. Rev. 115, 1990-2042 (2015).

8. Babii, O. et al. Direct photocontrol of peptidomimetics: an alternative to oxygen-dependent photodynamic cancer therapy. Angew. Chem. Int. Ed. 55, 5493-5496 (2016).

9. Dolmans, D. E. G. J., Fukumura, D. \& Jain, R. K. Photodynamic therapy for cancer. Nat. Rev. Cancer 3, 380-387 (2003).

10. Ju, E. et al. Copper(II)-graphitic carbon nitride triggered synergy: improved ROS generation and reduced glutathione levels for enhanced photodynamic therapy. Angew. Chem. Int. Ed. 55, 11467-11471 (2016).

11. Punjabi, A. et al. Amplifying the red-emission of upconverting nanoparticles for biocompatible clinically used prodrug-induced photodynamic therapy. ACS Nano 8, 10621-10630 (2014).

12. Zhou, Z. et al. Activatable singlet oxygen generation from lipid hydroperoxide nanoparticles for cancer therapy. Angew. Chem. Int. Ed. 56, 6492-6496 (2017).

13. Shen, S. et al. A hybrid nanomaterial for the controlled generation of free radicals and oxidative destruction of hypoxic cancer cells. Angew. Chem. Int. Ed. 56, 8801-8804 (2017).
14. Kolemen, S. et al. Remote-controlled release of singlet oxygen by the plasmonic heating of endoperoxide-modified gold nanorods: towards a paradigm change in photodynamic therapy. Angew. Chem. Int. Ed. 55, 3606-3610 (2016).

15. Kim, J. et al. Continuous $\mathrm{O}_{2}$-evolving $\mathrm{MnFe}_{2} \mathrm{O}_{4}$ nanoparticle-anchored mesoporous silica nanoparticles for efficient photodynamic therapy in hypoxic cancer. J. Am. Chem. Soc. 139, 10992-10995 (2017).

16. Li, W. P., Su, C. H., Chang, Y. C., Lin, Y. J. \& Yeh, C. S. Ultrasound-induced reactive oxygen species mediated therapy and imaging using a Fenton reaction activable polymersome. ACS Nano 10, 2017-2027 (2016).

17. Deepagan, V. G. et al. Long-circulating $\mathrm{Au}-\mathrm{TiO}_{2}$ nanocomposite as a sonosensitizer for ROS-mediated eradication of cancer. Nano Lett. 16, 6257-6264 (2016)

18. Zhang, Z., Zhang, X., Liu, B. \& Liu, J. Molecular imprinting on inorganic nanozymes for hundred-fold enzyme specificity. J. Am. Chem. Soc. 139, 5412-5419 (2017)

19. Asati, A., Santra, S., Kaittanis, C., Nath, S. \& Perez, J. M. Oxidase-like activity of polymer-coated cerium oxide nanoparticles. Angew. Chem. Int. Ed. 48, 2308-2312 (2009)

20. Gao, L. \& Yan, X. Nanozymes: an emerging field bridging nanotechnology and biology. Sci. China Life Sci. 59, 400-402 (2016).

21. Ragg, R. et al. Molybdenum trioxide nanoparticles with intrinsic sulfite oxidase activity. ACS Nano 8, 5182-5189 (2014).

22. Shi, W. et al. Carbon nanodots as peroxidase mimetics and their applications to glucose detection. Chem. Commun. 47, 6695-6697 (2011).

23. Zhang, $X$. et al. Highly efficient dendrimer-based mimic of glutathione peroxidase. J. Am. Chem. Soc. 126, 10556-10557 (2004).

24. Wang, X., Hu, Y. \& Wei, H. Nanozymes in bionanotechnology: from sensing to therapeutics and beyond. Inorg. Chem. Front. 3, 41-60 (2016).

25. Aioub, M., Panikkanvalappil, S. R. \& El-Sayed, M. A. Platinum-coated gold nanorods: efficient reactive oxygen scavengers that prevent oxidative damage toward healthy, untreated cells during plasmonic photothermal therapy. ACS Nano 11, 579-586 (2017).

26. Vernekar, A. A. et al. An antioxidant nanozyme that uncovers the cytoprotective potential of vanadia nanowires. Nat. Commun. 5, 5301-5314 (2014).

27. Zhang, W. et al. Prussian blue nanoparticles as multienzyme mimetics and reactive oxygen species scavengers. J. Am. Chem. Soc. 138, 5860-5865 (2016).

28. Zhang, Y. et al. Dietary iron oxide nanoparticles delay aging and ameliorate neurodegeneration in drosophila. Adv. Mater. 28, 1387-1393 (2016).

29. Huang, Y. et al. Self-assembly of multi-nanozymes to mimic an intracellular antioxidant defense system. Angew. Chem. Int. Ed. 55, 6646-6650 (2016).

30. Vernekar, A., Das, T., Ghosh, S. \& Mugesh, G. A remarkably efficient $\mathrm{MnFe}_{2} \mathrm{O}_{4}$-based oxidase nanozyme. Chem. Asian J. 11, 72-76 (2016).

31. Chen, Z., Wang, Z., Ren, J. \& Qu, X. Enzyme mimicry for bacteria and biofilms. Acc. Chem. Res. 51, 789-799 (2018).

32. Cai, S. et al. PtCo bimetallic nanoparticles with high oxidase-like catalytic activity and their applications for magnetic-enhanced colorimetric biosensing. J. Mater. Chem. B 4, 1869-1877 (2016).

33. Ge, J., Lei, J. \& Zare, R. N. Protein-inorganic hybrid nanoflowers. Nat. Nanotechnol. 7, 428-432 (2012).

34. Hu., L. et al. Symmetrical $\mathrm{MnO}_{2}$-carbon nanotube-textile nanostructures for wearable pseudocapacitors with high mass loading. ACS Nano 5, 8904-8913 (2011).

35. Deng, R., Xie, X., Vendrell, M., Chang, Y. \& Liu, X. Intracellular glutathione detection using $\mathrm{MnO}_{2}$-nanosheet-modified upconversion nanoparticles. J. Am. Chem. Soc. 133, 20168-20171 (2011).

36. Chen, H., Tian, J., He, W. \& Guo, Z. $\mathrm{H}_{2} \mathrm{O}_{2}$-activatable and $\mathrm{O}_{2}$-evolving nanoparticles for highly efficient and selective photodynamic therapy against hypoxic tumor cells. J. Am. Chem. Soc. 137, 1539-1547 (2015).

37. Zhu, W. W. et al. Modulation of hypoxia in solid tumor microenvironment with $\mathrm{MnO}_{2}$ nanoparticles to enhance photodynamic therapy. Adv. Funct. Mater. 26, 5490-5498 (2016)

38. Liu, X. et al. BSA-templated $\mathrm{MnO}_{2}$ nanoparticles as both peroxidase and oxidase mimics. Analyst 137, 4552-4558 (2012).

39. Wan, Y., Qi, P., Zhang, D., Wu, J. \& Wang, Y. Manganese oxide nanowiremediated enzyme-linked immunosorbent assay. Biosens. Bioelectron. 33, 69-74 (2012).

40. Gao, L. et al. Plasmon-mediated generation of reactive oxygen species from near-infrared light excited gold nanocages for photodynamic therapy in vitro. ACS Nano 8, 7260-7271 (2014).

41. He, W. et al. Photogenerated charge carriers and reactive oxygen species in $\mathrm{ZnO} / \mathrm{Au}$ hybrid nanostructures with enhanced photocatalytic and antibacterial activity. J. Am. Chem. Soc. 136, 750-757 (2014).

42. Wang, T. et al. Acidity-triggered ligand-presenting nanoparticles to overcome sequential drug delivery barriers to tumors. Nano Lett. 17, 5429-5436 (2017).

43. Zheng, $\mathrm{X}$. et al. Hypoxia-specific ultrasensitive detection of tumours and cancer cells in vivo. Nat. Commun. 6, 5834-5845 (2015).

44. Cheng, Y. et al. Perfluorocarbon nanoparticles enhance reactive oxygen levels and tumour growth inhibition in photodynamic therapy. Nat. Commun. 6 , 8785-8792 (2015) 
45. Wang, X. Q., Gao, F. \& Zhang, X. Z. Initiator-loaded gold nanocages as a light-induced free-radical generator for cancer therapy. Angew. Chem. Int. Ed. 56, 9029-9033 (2017).

46. Yuan, Y. et al. Specific light-up bioprobe with aggregation-induced emission and activatable photoactivity for the targeted and image-guided photodynamic ablation of cancer cells. Angew. Chem. Int. Ed. 54, 1780-1786 (2015).

47. Shah, B. P. et al. Core-shell nanoparticle-based peptide therapeutics and combined hyperthermia for enhanced cancer cell apoptosis. ACS Nano $\mathbf{8}$, 9379-9387 (2014).

48. Shao, J. et al. Biodegradable black phosphorus-based nanospheres for in vivo photothermal cancer therapy. Nat. Commun. 7, 12967-12979 (2016).

49. Klibanov, A. L., Maruyama, K., Torchilin, V. P. \& Huang, L. Protein adsorption patterns on parenteral lipid formulations-key factor determining the in vivo fate. FBBS Lett. 268, 235e237 (1990).

50. Song, G. et al. Catalase-loaded TaOx nanoshells as bio-nanoreactors combining high-z element and enzyme delivery for enhancing radiotherapy. Adv. Mater. 28, 7143-7148 (2016).

\section{Acknowledgements}

Financial support was provided by the National Nature Science Foundation of China (Grants 21431007, 21533008) and the Key Program of Frontier of Sciences, CAS QYZDJSSW-SLH052.

\section{Author contributions}

J.R. and X.Q. designed research; Z.W., Y.Z., E.J., Z.L., F.C., and Z.C. performed research; Z.W., Y.Z., E.J., Z.L., F.C., and Z.C. analyzed data; J.R. and X.Q. wrote the paper.

\section{Additional information}

Supplementary Information accompanies this paper at https://doi.org/10.1038/s41467018-05798-x.

Competing interests: The authors declare no competing interests.

Reprints and permission information is available online at http://npg.nature.com/ reprintsandpermissions/

Publisher's note: Springer Nature remains neutral with regard to jurisdictional claims in published maps and institutional affiliations.

(c) (i) Open Access This article is licensed under a Creative Commons Attribution 4.0 International License, which permits use, sharing, adaptation, distribution and reproduction in any medium or format, as long as you give appropriate credit to the original author(s) and the source, provide a link to the Creative Commons license, and indicate if changes were made. The images or other third party material in this article are included in the article's Creative Commons license, unless indicated otherwise in a credit line to the material. If material is not included in the article's Creative Commons license and your intended use is not permitted by statutory regulation or exceeds the permitted use, you will need to obtain permission directly from the copyright holder. To view a copy of this license, visit http://creativecommons.org/ licenses/by/4.0/.

(C) The Author(s) 2018 